Sustainability Solutions -

Lessons on Assessment

and Facilitation

Axel Lindfors

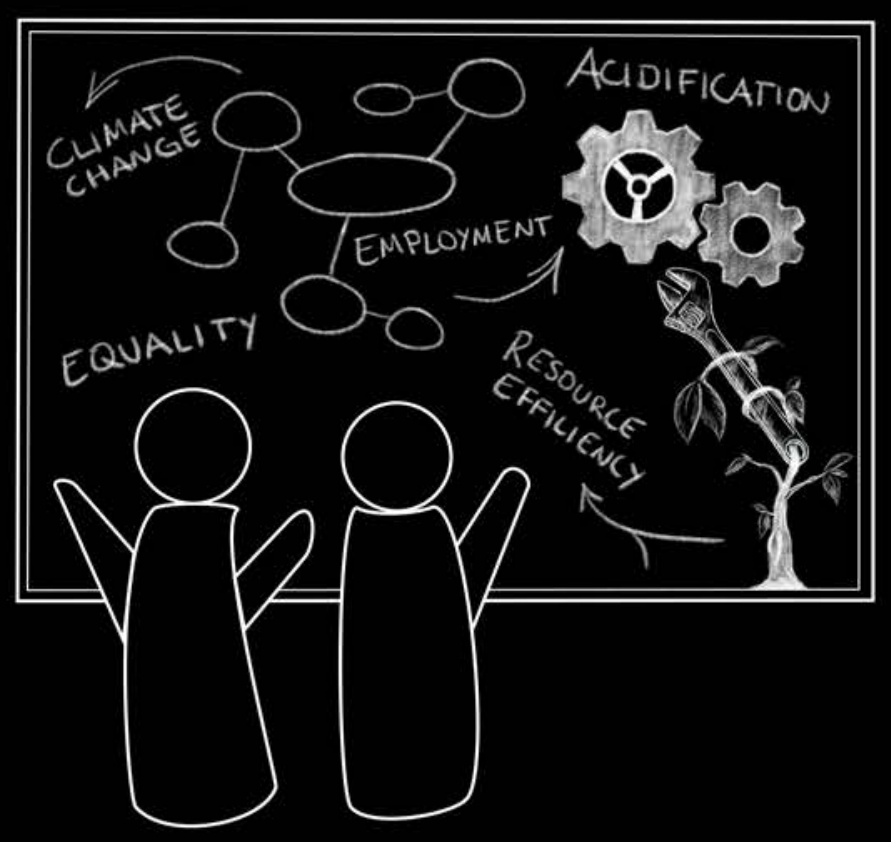




\title{
Sustainability Solutions - Lessons on Assessment and Facilitation
}

\author{
Axel Lindfors \\ Environmental Technology and Management \\ Department of Management and Engineering \\ Linköping University, SE-581 81 Linköping, Sweden \\ www.liu.se
}


(C) Axel Lindfors, 2020

Sustainability solutions - Lessons on Assessment and Facilitation

Linköping Studies in Science and Technology

Licentiate Thesis No. 1875

ISBN: 978-91-7929-870-8

ISSN: 0280-7971

Printed by LiU-Tryck, Linköping 2020

Cover design: Elin Borin

Distributed by:

Linköping University

Department of Management and Engineering

SE-581 81 Linköping, Sweden 
Why may not a goose say thus: "All the parts of the universe I have interest in: the earth serves me to walk upon, the sun to light me; the stars have their influence upon me; I have such an advantage by the winds and such by the waters; there is nothing that yon heavenly roof looks upon so favourably as me. I am the darling of nature! Is it not man that keeps and serves me?"

Michel de Montaigne, 1533 - 1592 



\section{Abstract}

Sustainable development is one of the most influential visions guiding future societies. Encompassed within its vision are various domains where improvements are desirable such as, social equity, environmental degradation, climate change. In the work towards sustainable development firms, government authorities and individuals face various practical challenges tied to these sustainability domains. When facing these challenges, they may implement sustainability solutions, that is, solutions that are framed in the context of contributing to sustainable development. This thesis deals with a particular sub-set of such sustainability solutions, namely integrative and multi-functional solutions. These solutions are characterized by the ability to provide different functions through value creation within several different sustainability domains and require organisations, or units of organisations, to further integrate material, energy and informational flows in order to implement the solution. Integrative and multi-functional solutions may play an important part in the transition towards sustainable societies since the integration of material, energy and informational flows may bring with it synergistic benefits. Furthermore, the contribution of these solutions to several different sustainability domains reduces the risk of problem shifting, and it may be more cost-efficient to have one multi-functional sustainability solution than to have one for each sustainability-related challenge.

However, if integration and multi-functionality are desirable characteristics of future socio-technological systems, we need ways to systematically assess them and facilitate their implementation. When it comes to the assessment, there is a need to find an assessment methodology that can handle capturing the synergistic benefits and multiple functions of such solutions. Furthermore, the methodology also has to conform to the value pluralism inherent to sustainable development. Dealing with this value pluralism when trying to assess which solution, among many, to implement can be challenging as comparative judgements have to handle potentially conflicting value orientations, goals, empirics and ontologies. As for the facilitation of their implementation, integrative and multi-functional solutions tend to be more difficult-or at least different-to implement than traditional single-minded solutions since they require traditionally separate organisations to cooperate Therefore, this thesis aims to contribute to understanding the process of implementing integrative and multi-functional solutions. Specifically the thesis explores how to select indicators for assessment, how assessments may aid decision-makers to deal with the value pluralism of sustainable development when making comparative judgements and how to strengthen the internal capacity of groups of actors to engage in collective action.

Regarding the selection of indicators, the thesis suggests two different pathways. Either one may base indicator selections on stakeholder discussions, where stakeholders come to a consensus around which indicators are important to assess, or one may base indicators on operationalising pre-defined sustainability objectives: namely, sorting, contextualising and reformulating pre-defined sustainability objectives so that they fit the purpose of the assessment. A mix of both pathways is also possible, in other words, using both stakeholder discussions and the operationalisation of pre-defined sustainability objectives to motivate and justify the selection of indicators. As for how assessments may aid decision-makers, the thesis advocates for a discursive approach based on the primacy of decision support tools over decision-making 
tools. Meaning that the tools should support informed decisions but not make them for the decisionmaker. Here, contributions are made in the form of motivations for the discursive, qualitative approach to decision-making and exemplify how decision support tools may be designed, and a method is presented and developed that enables this kind of informed comparative judgements. This method builds on multicriteria decision analysis methodology but makes a few key contributions to the selection of indicators (mentioned previously) and to how to compare different alternatives and judge which of the alternatives is the preferred. Finally, contributions are made to the practice of facilitating integrative and multi-functional solutions through showing how the theory of institutional capacity building can be used to guide design, development and evaluation of interventions aimed at facilitating such solutions. Institutional capacity building represents the ability of groups of actors to engage in collective action, something that seems to be often needed to implement integrative and multi-functional solutions. Historically, this theory has been used to study how different events influenced the capacity of actors to engage in collective action. However, in research performed within the bounds of this thesis, the theory is expanded for use in a proactive manner, thereby contributing with insights and inspiration to others that may seek to facilitate the implementation process of integrative and multi-functional solutions. 


\section{Acknowledgements}

First, I would like to acknowledge the importance of the Biogas Research Center (BRC), the competence centre that has funded the majority of the research in this thesis. In addition to funding the research, the BRC has served as an arena where this research has been presented, discussed and critically review, for which I am deeply grateful. I hope that I may continue to take part in insightful discussions, fruitful workshops and conducive meetings during the remainder of my doctoral studies. Next, a huge thank you goes out to my supervisors, Mats Eklund and Roozbeh Feiz, their aid throughout the first years of my doctoral studies have been priceless. Whether it has to do with broad questions such as framing and scoping issues or small details such as word choices, you have always been there to help. I very much appreciate that I am able to reach out to you two whenever I hit roadblock and that you are there to provide helpful guidance in order for me to overcome any roadblocks. I look forward to continue doing research and writing articles with the two of you, not just for the rest of my doctoral studies, but during the rest of my academic career. A big thank you as well to Jonas Ammenberg, an amazing researcher, a great co-author and an exceptional research and unit leader. Your diligent planning, sharp comments, high standards and unflinching research-ethical compass is an asset to any research community. Another big thank you to Linda Hagman, my office roommate and research colleague. Your company, knowledge and insightful comments have helped me through many difficult times. To all of my colleagues at the division of environmental technology and management at Linköping University, thank you so much. You have provided me with the best research environment a doctoral student could ever imagine. Furthermore, my lovely girlfriend Elin, thank you so much for putting up with me working late and during weekends, and thank you for the amazing work with the cover design. What you bring to my life is beyond words so I will not attempt to capture it here, but again, thank you. Finally, a big thank you to my parents, Mats and Marie, thank you so much for feeding, raising and supporting me throughout all of my life. You have been the best parents anyone could ever ask for, and I know you will continue to be as I continue my journey through life. 


\section{List of Appended Papers}

Paper I: Lindfors A., Feiz R., Eklund M. \& Ammenberg J., Assessing the Potential, Performance and Feasibility of Urban Solutions: Methodological Considerations and Learnings from Biogas Solutions, 2019, published in Sustainability v.11 i.14 p.3756

Contribution: The first author came up with the idea and concept for the paper in conjunction with the co-authors, wrote the first draft of the paper and edited it after input from the co-authors.

Paper II: Lindfors A. \& Ammenberg J., Using national and international environmental objectives in green public procurement, Manuscript

Contribution: The first author created the methodology together with the co-author, gathered data and wrote the first draft of the paper. Comments and suggestions were received by the co-author throughout the process.

Paper III: Lindfors A., Gustafsson M., Anderberg S., Eklund M. \& Mirata M., Developing biogas systems in Norrköping, Sweden: An Industrial Symbiosis Intervention, Under review, Journal of Cleaner Production

Contribution: All authors participated in gathering data and performing the workshops described in this paper. The first author, together with the second author, wrote the first draft of the paper and edited it after suggestions from the other co-authors. The first and last author built the theoretical and analytical framework used to evaluate the internal capacity of the network and how it had increased.

\section{Related publications}

Related Publication I: Lindfors A., Eklund M. \& Peltonen Ramkvist E., Östergötlands potential för biodrivmedelproduktion och utökad elektrifiering, Region Östergötland, Linköping, Sverige

Related Publication II: Lindfors A. \& Eklund M., Samhällseffekter av alternative drivmedel, Region Östergötland, Linköping, Sverige

Related Publication III: Gustafsson M., Lindfors A., Anderberg S., Ammenberg J. \& Eklund M., Biogaslösningar i Norrköping - potential för produktion och marknad, Biogas Research Center, Linköping, Sverige 


\section{Content}

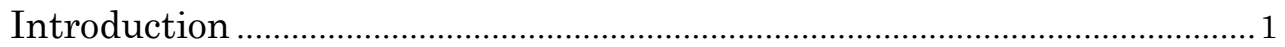

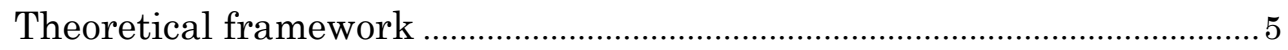

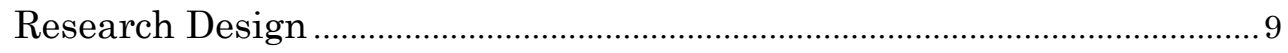

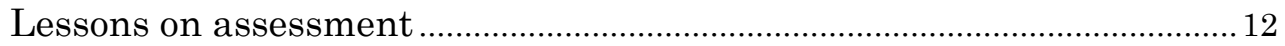

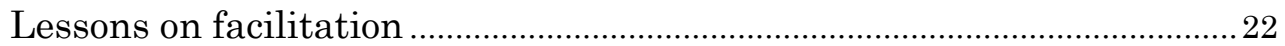

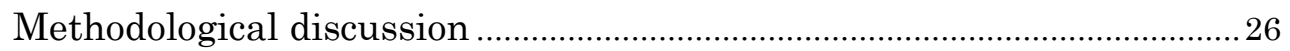

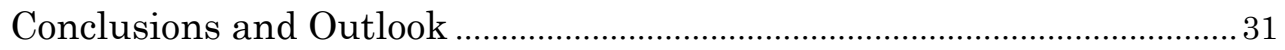

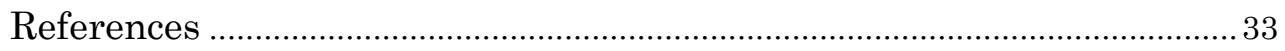

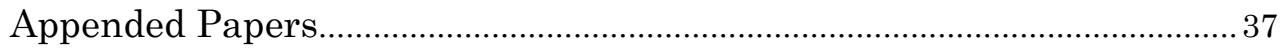




\section{List of Figures and Tables}

Figure 1. Three types of natural and industrial ecosystems, ranging from linear to cyclic systems. Based on Jelinski et al. (1992)

Figure 2. The theoretical framework for how institutional capacity is built and how it influences industrial symbiosis networks. Based on Spekkink (2016).

Figure 3. The procedure of the multi-criteria decision analysis method used in this thesis (Paper I).

Figure 4. Suggested pathways for defining the multi-criteria assessment framework and its elements....

Table 1. A list of recommended key areas, along with some suggested key questions, to consider when assessing the sustainability performance and feasibility of integrative and multi-functional solutions.

Table 2. Examples of normative scales used in the public procurement tool in Paper II 18

Table 3. The interactions suggested by Boons et al. (2014) as interactions that build institutional capacity within networks. How these interactions were performed in the Norrköping workshop series is also briefly described (Paper III) 



\section{1 \\ Introduction}

Sustainable development, one of the most influential visions of future societies, represents a pluralistic value framework. It is comprised of several different domains where improvement is desirable, such as living standards, social equity, use of non-renewable materials and fuels and ecosystem health (United Nations, 1987). Each of these domains is affected through complex causalities where it is often difficult to explain definitively that a certain action has contributed towards a particular sustainability domain and, as such, to sustainable development. Nevertheless, many individuals, organisations and nation-states claim to be working with sustainable development. In this endeavour, one may employ sustainability solutions, in other words, solutions that aim to contribute towards sustainable development and are that framed in a sustainability context ${ }^{1}$. Implementing sustainability solutions that address several sustainability-related challenges ${ }^{2}$ simultaneously-hence contributing towards several sustainability domains-may play a major part in the sustainable development of societies (Korhonen, 2004a; Matson, 2001). The reason for this is that if each sustainability-related challenge is addressed in isolation, there is a risk of creating sub-optimal solutions. Such solutions may, when the costs of each individual solution are added together, become more expensive than what one solution addressing several challenges simultaneously would have been. In addition, narrow sustainability solutions bring with them risks of new problems arising in other sustainability domains because these domains were not considered when the solution was implemented, something known as problem shifting (Korhonen, 2004a).

Simultaneously addressing several sustainability-related challenges creates multiple functions, both in the sense that multiple actors receive some function and because the solution has multiple functions through its contribution to various sustainability domains. Furthermore, these solutions may benefit from further integration of material, energy and informational flows in their implementation (Frosch and Gallopoulos, 1989; Mirata and Emtairah, 2005; Porter and van der Linde, 1995). Part of the reason for this is that integrated implementation may overcome issues with lack of financial means, knowledge or authority since several actors may join forces and pool resources. Another part is that they bring with them synergistic benefits (Frosch and Gallopoulos, 1989; Park et al., 2016; van Berkel et al., 2009). Common synergistic benefits include the various economic and environmental benefits of utilizing by-product and

\footnotetext{
${ }^{1}$ Note that sustainability solutions do not have to be sustainable solutions, they only aim to be or are framed in such a way.

${ }^{2}$ The specific practical challenges that individuals-or groups of individuals-face when working towards sustainable development.
} 
waste flows as input into other manufacturing processes (Porter and van der Linde, 1995), and the knowledge sharing and increased innovation capacity stemming from closer collaboration between actors (Mirata and Emtairah, 2005). Sustainability solutions that are characterised by both these aspects, namely that they create multiple functions and further integrate material, energy and informational flows between organisations, are in this thesis referred to as integrative and multi-functional solutions.

This concept, which is used throughout the thesis, enables discussion and deliberation about a group of sustainability solutions that address different sustainability-related challenges simultaneously in an integrative manner. Since this is a concept widely used in the thesis, understanding what integrative and multi-functional solutions entail is important. As such, some short sentences are dedicated to the explanation of the concept here in the introduction. First, there is no defined set of technologies that may or may not be thought of as integrative and multi-functional; instead, it is how the technology is designed and implemented that decides to what degree it is integrative and multi-functional. Moreover, being integrative and multi-functional is not a binary state but should be thought of as a scale, where solutions can be more or less integrative and multi-functional than other sustainability solutions. Furthermore, one should not think of it as two separate adjectives but one, meaning that there is not a sub-set of integrative solutions, and they have some characteristics and vice versa. Instead, integrative and multi-functional solution is one concept, and characteristics that these solutions hold cannot be separated into integrative characteristics and multi-functional characteristics. In addition, these solutions exist on the societal level, meaning that the concept is concerned with solutions to societal challenges such as how to provide citizens with their mobility needs, how to recirculate nutrients from waste to farmlands or how to provide longterm clean water to a city's inhabitants.

To enable the validation of integrative and multi-functional solutions, one may assess these solutions to understand their contribution towards various sustainability domains, their short-term economic viability and their feasibility of implementation. This assessment would present knowledge to decision-makers that enable informed decisions regarding whether to move forward with the implementation process or not. Examples of decision-making processes where this could be needed include setting requirements for public procurement; prior to decisions on policy implementation; strategic planning of cities; or when deciding whether to implement large infrastructure changes. As decision support for these kinds of decisions, assessments of integrative and multi-functional solutions require a broad system perspective, including relevant impact areas that systematically depict impacts on different sustainability domains and include the entire life-cycle of the solution. This is important both to ensure that all benefits and costs of the assessed solutions are accounted for and to avoid problem shifting (Korhonen, 2004a; UNEP/SETAC, 2005). Today, it is common to focus on a single sustainability domain in isolation, such as climate change, equity, health or biodiversity, while one should preferably consider all relevant domains to the decision at hand in an integrated manner (Blanc, 2015; Stafford-Smith et al., 2017). Similarly, government organisations tend to work in silos, either connected to a certain service provision (e.g., energy, education and health) or a certain industrial sector (e.g., agriculture, material extraction and forestry) 
(Healey et al., 2003, p. 60), meaning that integrative and multi-functional solutions may struggle to become attractive options as the narrow mindset constricts these organisations from appreciating the broader set of values these solutions bring. This silo idea is not limited to governmental organisations but appears in firms (and the division of firms) as well. To exemplify, imagine an organisation with the goal of generating as much money as possible by producing metals in the most resource-efficient way. Such an organisation will not care if a solution also happened to be an environmental remediation, increases land value or increases the amount of recycled materials in society. What is important is simply the value of the metals and the cost of producing them. This way of thinking and acting is inherently opposed to the value pluralism of sustainable development.

The requirement of handling value pluralism and a broad (and relevant) system perspective presents challenges to those seeking to assess integrative and multi-functional solutions. One challenge is tied to the difficulty of knowing what set of indicators will be broad enough on which to base the assessment. The question of what set of indicators may be broad enough to cover relevant areas without causing analytical paralysis ${ }^{3}$ is a difficult one to answer. Indeed, increased transparency and a more structured approach to selecting indicators have been highlighted in a recent literature review on multi-dimensional assessments of road transportation (Kügemann and Polatidis, 2020), indicating that this is a question with which many researchers struggle. In addition, if one can find a set of indicators that are broad enough and agree on what options should be considered as well as what their sustainability impacts are, there is still one challenge that remains. How should decision-makers prioritise between different-sometimes conflicting-sustainability domains? Because these solutions address several sustainability-related challenges, it is rare that one organisation has the authority over all areas that are affected by implementing the solution. As such, several actors may have to band together to gain the authority and combined resources to implement integrative and multi-functional solutions. These actors then need to decide together on what actions are desirable. Hence, investigating the processes of selecting indicators and the process of deciding whether to move forward with the implementation of a certain solution may provide fruitful insights to these actors and to the methodology of multi-dimensional assessments.

While assessments may play an important role in the process of implementing integrative and multifunctional solutions, many other challenges remain. Another challenge comes from the increased demand for integration between organisations, which creates a potential need to pool resources and engage in collective action in order to implement integrative and multi-functional solutions. This is different from the traditional way of each organisation implementing their own solution(s) in isolation (see the part about silo thinking in organisations earlier in the introduction). This thesis, in order to understand how integration and collective action may occur, draws upon ideas from the field of industrial symbiosis. Industrial symbiosis refers to the process of connecting material, water or energy flows between actors through the utilization of secondary resources or through utilities and service sharing, often with the cobenefit of increased environmental performance (Boons et al., 2017). As such, the field is relevant to

\footnotetext{
${ }^{3}$ This is what Hertwich et al. (1997) defines as the inability to use the assessment due to information overload or too large informational requirements.
} 
understanding integrative and multi-functional solutions since these solutions often build upon utilizing secondary resources or utility and service sharing in order to enable contribution towards multiple sustainability-related challenges. Industrial symbiosis has a rich history of investigating how one may facilitate integration between actors and the coordination and pooling of resources (e.g., Doménech and Davies, 2011; Jacobsen and Anderberg, 2004; Mirata, 2004; Paquin and Howard Grenville, 2012). To this end, Mirata (2004) suggests a categorization of five determinants that may determine the likelihood of successful implementation of industrial symbiosis synergies, namely, technical, political, economic, informational and organizational determinants. Furthermore, Mirata (2005) highlights that while working on all determinants simultaneously provides the most promise for creating a fertile development setting, an initial focus on influencing determinants through the internal capacities of the actor group often requires fewer resources and provides quicker results. As such, the focus of this thesis is also on how one may strengthen the internal capacity of groups of actors to facilitate implementation of integrative and multifunctional solutions.

With this introduction, this thesis aims to contribute to understanding the process of implementing integrative and multi-functional solutions. Specifically, the thesis explores how to select indicators for assessments that ensure a broad, relevant and systematic assessment; how assessments may aid decisionmakers to deal with the value pluralism of sustainable development when making comparative judgements; and how to strengthen the internal capacity of groups of actors to engage in collective action.

Research Question 1: $\quad$ How may indicators be selected to ensure that assessments based on these indicators are relevant and broad enough to encompass the impact of integrative and multi-functional solutions on different sustainability domains while keeping the assessment practically feasible?

Research Question 2: $\quad$ How ought assessments of integrative and multi-functional solutions be designed and performed to properly support decisions that affect the process of implementing such solutions?

Research Question 3: $\quad$ How can interventions be designed that enable a strengthening of the internal capacities of groups of actors to engage in collective action toward the implementation of integrative and multi-functional solutions? 


\section{2 \\ Theoretical framework}

The theoretical origin of the concept of integrative and multi-functional solutions brought forward in this thesis comes from the field of industrial ecology. While other theories are important to the assessment and facilitation of integrative and multi-functional solutions, the concept as such and its characteristics have their origin in industrial ecology. The field of industrial ecology is built on the vision of designing and operating our industrial systems like ecosystems. Its origin comes from the idea that manufacturing industries could be more efficient and less environmentally harmful should they utilize secondary resources as inputs, leading to industrial systems that create less waste (Frosch and Gallopoulos, 1989). From this spark, a theory emerged with the central tenant that industrial systems should liken themselves to those of natural ecosystems in order to reduce environmental harm and resource consumption (Graedel and Allenby, 1995; Korhonen, 2004b). Here, industrial systems are not only manufacturing industries but instead all parts that make up an industrialized society. Commonly, the desirable transformation of the industrial system according to industrial ecology is envisioned through three types of systems first described by Jelinski and colleagues (1992) and shown in Figure 1. The Type I system is characterized by linear material and energy flows, where inputs are treated as being unlimited and waste production is unchecked. In the Type II system, a few connections between system components are made to enable some reuse and recycling. Thus, the resource flow into the system is lowered, and material and energy are utilized more efficiently than in a Type I system. Finally, the Type III system, the ideal system, is achieved when the only input into the system is solar energy, and nothing other than excess heat leaves the system. Ensuring that materials are used time and time again both through downcycling (using materials several times before the material is discarded, each time the value of the material reduces, e.g., reselling used but functional products) and upcycling (refining materials to create higher value from outputs than inputs, e.g., producing clothes from plastic waste). This maximizing of value while reducing material input and pollutant output contributes towards both the economic and ecological dimensions of sustainability in a win-win sense (see, e.g., Porter and van der Linde, 1995). 


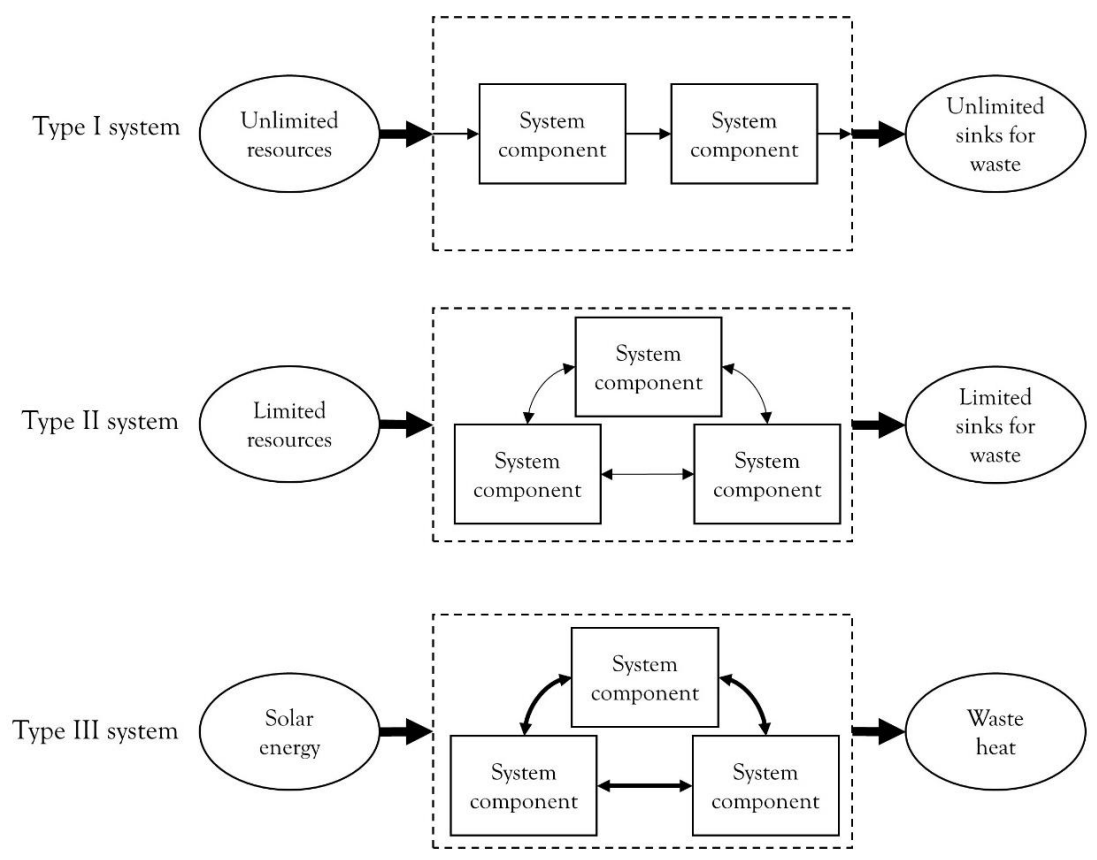

Figure 1. Three types of natural and industrial ecosystems, ranging from linear to cyclic systems. Based on Jelinski et al. (1992)

Because industrial ecology is focused on closing material cycles, the life-cycle perspective is a core part of the theory. To have a life-cycle perspective means looking at the entire life-cycle of products, services or materials, from cradle to grave, or hopefully, another cradle if the material cycles are closed (Feiz, 2016). In order to assess to what extent solutions are integrative and multi-functional, a life-cycle perspective is necessary. Otherwise, one risks missing important functions, environmental emissions or negative social consequences, which may lead to sub-optimization or problem shifting (Korhonen, 2004a). Furthermore, industrial ecology also puts emphasis on the importance of decreasing the toxicity of material flows. This is sometimes seen as a given in the pursuit to liken industrial systems to ecosystems (since toxicity levels are generally low in ecosystems if they function well). In addition, reducing the toxicity of industrial material flows can also provide an additional puzzle piece towards achieving Type III systems, namely, that cyclic processes in nature can be used to recycle materials. For example, the by-product of anaerobic digestion-digestate-can be applied in farms and fields (assuming it is not toxic), and new crops can utilize the nutrients, trace elements and organic matter to grow (Al Seadi et al., 2013). Hence, recycling of the digestate is handled through partly through natural ecosystems.

However, even achieving a Type II industrial system will not be easy. It will require the integration of different sub-systems and sectors as well as a highly effective waste management sector (Korhonen, 2004a). This is where the concept of integrative and multi-functional solutions appears as a way to characterize and group solutions that contribute towards closing material cycles through further integration of material and energy flows and reducing environmental harm through various pro-environmental added 
values. Furthermore, they may have other sustainability-related benefits in the realms of economic or social sustainability (Huber, 2000; Korhonen, 2004a; Porter and van der Linde, 1995). As such, integrative and multi-functional solutions can be seen as solutions based on (some) industrial ecology principles.

The integration between different industrial sectors that Korhonen (2004a) speaks of will, unfortunately, not happen by itself. It is commonsensical to think that integrative and multi-functional solutions are more difficult to implement than non-integrative solutions due to the need to coordinate, overcome silo thinking and come to a consensus between actors with sometimes differing opinions, goals and value orientations. While it is difficult to prove that integrative and multi-functional solutions are more difficult to implement than other sustainability solutions, one thing is for certain, that their integrative nature means the process of implementation differs in some ways from conventional solutions. Hence, new ways of facilitating implementation are needed. As stated in the introductory chapter, the thesis draws upon the industrial symbiosis literature to understand how the facilitation of collective action towards the implementation of integrative and multi-functional solutions can be done. To this end, several industrial symbiosis scholars stress the importance of social factors such as trust, shared visions and common norms for the successful development of industrial symbiosis initiatives (see, e.g., Ashton, 2008; Boons et al., 2011; Hewes and Lyons, 2008; Mirata, 2005; Park et al., 2018). Thus, the facilitation of industrial symbiosis has to influence these social factors in a positive way. The approach to influencing the social factors affecting industrial symbiosis development applied in this thesis builds on an idea put forth by Mirata (2005), namely, that an initial focus on the internal capacities of networks to self-organise and develop synergies often requires fewer resources and provides quicker results. However, it is important to understand that industrial symbiosis development does not appear in a vacuum; rather, various institutional contexts $^{4}$ shape the ability of groups of actors to develop synergies. Even so, the focus of this thesis is on strengthening the internal capacities of networks to engage in industrial symbiosis development under various institutional contexts. This means that some aspects of how to influence the institutional context and in what direction the context should be influenced in is left outside the scope of the thesis.

This research, in order to help understand the internal capacities of industrial symbiosis networks, draws upon the theory of institutional capacity building in industrial symbiosis networks proposed by Boons and colleagues (2011) and further developed by Boons and Spekkink (2012) and Spekkink (2016, $2015,2013)$. This theory originates in network policy analysis and was originally developed by Healey (1998) and Healey and colleagues (2003) to understand how actors come together to address issues of common concern and how this complex process may be analysed. Issues of common concern may, for example, be how to improve local business performance, local living standards or various governance aspects such as policy. Institutional capacity is seen as a "force which is continually emergent, produced in the interactive contexts of its use" (Healey et al., 2003, p. 63), meaning that it exists in the interactions between actors.

\footnotetext{
${ }^{4}$ Institutional contexts represent external factors that shape interaction within the networks. These may, for example, be subtle influences like cultural norms or more tangible ones such as laws or regulations (Spekkink, 2016).
} 
Institutional capacity building can be understood through the following three dimensions (Boons et al., 2011; Healey et al., 2003):

- Relational resources, which is characterized by the number of involved actors in the network and the quality of interactions between them as well as their trust in each other.

- Knowledge resources, which represents the knowledge level within the network, the capacity of the network to absorb new ideas and how well perceptions of problems, barriers, solutions and opportunities are aligned within the network.

- Mobilization capacity, which is the ability of actors, or the network, to engage additional actors who may support the implementation of identified solutions. It also includes the presence or absence of shared visions and leaders.

To build institutional capacity, these three dimensions must be strengthened. Boons et al. (2014) suggest several basic interactions that may do just that. These are orientation, planning, feasibility studies, implementation, influencing other actors, declaration, establishing new organisations, strategic visioning and influencing the context. These interactions do not necessarily have to include all actors within an industrial symbiosis network. Interactions that occur within projects that include a portion of the network may still increase the entire network's institutional capacity (Spekkink, 2016). Figure 2 describes the theoretical framework conceptualised by Spekkink (2016) for how institutional capacity influences and is influenced by the development of industrial symbiosis.

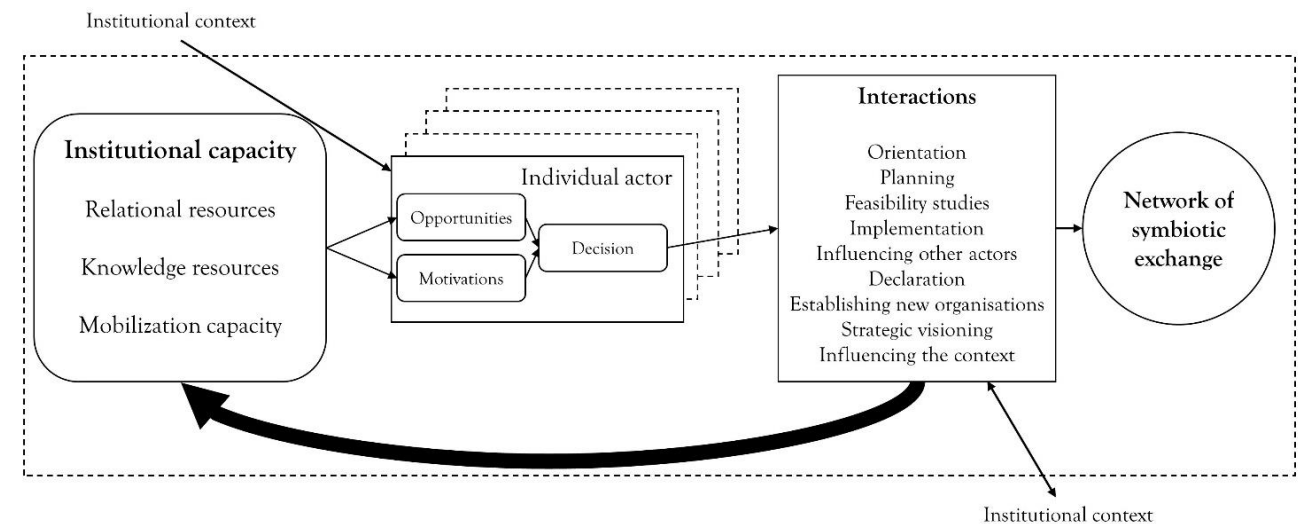

Figure 2. The theoretical framework for how institutional capacity is built and how it influences industrial symbiosis networks. Based on Spekkink (2016). 


\section{3}

\section{Research Design}

To cover the implementation process of all possible solutions that may be integrative and multi-functional is an impossible task, as there is an infinite number of solutions that may be more or less integrative and multi-functional. As such, this research tackles its research questions through an exploratory approach based on Wittgenstien's metaphor for learning philosophy (quoted in Gasking and Jackson, 1962, p. 52). Namely, that one should think of the subject matter as a city and if one traverses the city from north to south, and from east to west, and continues to take many different journeys through the city, one will, in the end, know the city. In this sense, I have traversed the metaphorical streets of how to assess and facilitate the implementation of integrative and multi-functional solutions. Nevertheless, I have only made a few trips, and as such, I do not claim to be able to cover all aspects, topics and theories related to the process of implementing integrative and multi-functional solutions. Instead, based on these journeys, I have collected what insights I have induced in this thesis. These theoretical and methodological contributions are presented alongside-and discussed in relation to-relevant previous theories, methods and empirical knowledge in two chapters (Chapters 4 and 5). In addition, discussions that are relevant for the methodology of the licentiate or the entire implementation process of integrative and multi-functional solutions are dealt with in Chapter 6. What follows in this chapter are short descriptions of my research journeys that have been the empirical basis for the theoretical and methodological contributions of this thesis.

The first journey followed alternative fuels (e.g., HVO, ethanol, electricity and biogas) and how to assess their impact on different sustainability domains. This journey started with a research project called Sustainable Transportation in Östergötland ${ }^{5}$ (author's translation, sv. Hållbara Transporter i Östergötland). The project was conducted together with representatives from the regional authority in Östergötland, the county administration and the regional public transportation company. The aim was to explore Östergötland's potential to increase the production and use of alternative fuels, namely, biofuels and electricity. This was done through 1) a study investigating the biomass potential in Östergötland for production of biofuels and the ability of the power grid to handle an expansion of electrical vehicles and 2) an assessment of each fuel type's contribution towards sustainable development in Östergötland. A more thorough background and explanation of the project can be found in Related Publications I and II.

\footnotetext{
${ }^{5}$ Östergötland is a county in the southeast of Sweden.
} 
The second journey continued along the lines of assessing alternative fuels, but with a new focus: how to integrate this assessment into the public procurement process in Sweden. Together with Biodriv Öst ${ }^{6}$, research was initiated to support public actors when they procured public transportation. The aim was to assess how different fuel systems contributed positively or negatively to the fulfilment of the Swedish environmental quality objectives. Based on the these objectives, a decision-support tool was constructed. The tool utilizes six criteria and eight indicators to assess the impact of different fuel systems on the Swedish environmental quality objectives. The decision-support tool was continuously presented and discussed at workshops, conferences and meetings where feedback was given by procurers, transportation solution providers, vehicle manufacturers, fuel suppliers, public officials and civil servants. This led to the creation of an excel-based tool that allowed procurers access to data for how 18 different fuels contribute to the Swedish environmental quality objectives. The tool also has a built-in function for translating the environmental performance to monetary value. Paper II is based on this research.

Finally, the third journey focused on how to facilitate the implementation of biogas solutions ${ }^{7}$ in the municipality of Norrköping, Sweden. The Biogas Research Center initiated a workshop series, which was performed with several different actors, each with a stake in different parts of the biogas value chain. During three workshops, these actors, together with researchers from the Biogas Research Center, worked to facilitate the implementation of biogas solutions in Norrköping through knowledge building and the strengthening of actor relations. Specifically, the first workshop aimed at forming a collective understanding of the current biogas system in Norrköping and getting different actors acquainted with each other. During the time in between Workshops 1 and 2, a potential and feasibility study was performed to investigate the biogas potential from different biomass sources in Norrköping and the feasibility of realizing this potential. This material was presented and discussed in Workshop 2. From these discussions, a few key barriers, opportunities and key actors were distilled, which allowed Workshop 3 to focus on how the key barriers could be overcome, how the key opportunities could be exploited and who were the key actors to lead the work. The research performed here provided the basis for Paper III.

As for how these journeys have contributed to insights detailed in the rest of the thesis, research journeys one and two contributed mainly to findings in Chapter 4, while research journey three contributed primarily to findings in Chapter 5 . As the reader might note, these journeys have been following the transportation system and especially sustainable transportation, but these journeys branch out to other large technical systems like the waste and wastewater management system, the agriculture system and the energy system because of the integrative and multi-functional nature of the solutions under study.

\footnotetext{
${ }^{6}$ Biodriv Öst is a network operating in the east of Sweden with the aim of accelerating the transition away from fossil fuels in the Swedish transport sector.

${ }^{7} \mathrm{~A}$ biogas solution refers to socio-technical systems where biogas plays an integral part. This can, for example, be a public transportation system running on upgraded biogas generated from household waste. The concept of biogas solution does not imply that the biogas is sourced from a certain input material nor that it is used in a certain way.
} 
Furthermore, all research journeys-and thus, the research as a whole-originate from real-world challenges ${ }^{8}$. As such, the research adopted a transdisciplinary approach, one tailored to real-world based research (Pohl, 2011) and common to research dealing with sustainable development (Brandt et al., 2013). Transdisciplinary research means doing research beyond the conventional scientific disciplines; it also means doing research that integrates knowledge from several different disciplines and practitioners, as well as answering research questions based on real-world challenges (Pohl, 2011). In practice, this means that research questions originate in the real world and that research methods are chosen and developed with stakeholders, as well as that result interpretation is done together with stakeholders. It should be noted that while the origin of the research comes from real-world challenges, the research itself does not necessarily need to address said challenges directly. For example, descriptive research trying to understand the origin of a certain real-world problem may be transdisciplinary while not directly contributing any potential solutions to the challenge. This real-world origination often means that transdisciplinary science needs to utilize knowledge from many disciplines-as the world is unfortunately not divided into orderly disciplines-in order to answer posed research questions. That is, the research needs to go beyond traditional disciplinary partitions, hence the name transdisciplinary. Furthermore, practitioners and stakeholders are often involved throughout the research process to ensure that the basis of the research questions is correctly understood and that the relevance of the result is high. Through this inclusion, results are codeveloped, and learning may be shared between the researcher and other participants of the research (Blok et al., 2015).

\footnotetext{
${ }^{8}$ Here real-world challenges refer approximately to practical challenges that exist partly beyond the minds of people. Examples of challenges that are not real-world challenges are challenges of a purely theoretical nature or that exist within models, simulations or scenarios.
} 


\section{4 \\ Lessons on assessment}

The introduction briefly touched upon the difficulties of assessing in what way and to what extent a solution is integrative and multi-functional, in other words, what its contribution towards various sustainability-related challenges is and how it achieves this contribution. The difficulties in focus in this thesis arise from two main parts. First, the assessment requires a method capable of handling a wide variety of different sustainability domains, namely, a multi-dimensional and value-pluralistic assessment method. Second, because we are interested in the eventual implementation of the solution, there is a need to understand its feasibility.

In order to perform multi-dimensional assessments, including both various sustainability domains and feasibility aspects, this research builds on soft multi-criteria decision analysis (MCDA), sometimes also known as multi-criteria decision-making or multi-criteria assessment. Soft MCDA methods are used for knowledge structuring and analysis to support decisions rather than deciding which option is optimal; in other words, they are decision support tools rather than decision making tools (Mendoza and Martins, 2006). As was shown in Paper I, soft MCDA can include a wide variety of aspects that are deemed important, including multiple sustainability domains and feasibility aspects. Furthermore, they allow assessment even in the presence of differing value orientation and goals (Martinez-Alier et al., 1998), while also being able to handle both quantitative and qualitative information (Mendoza et al., 1999), something common when assessing sustainability domains and feasibility aspects. The procedure of the MCDA of this thesis builds upon the five steps common to many MCDAs (see, e.g., Kumar et al., 2017; Pohekar and Ramachandran, 2004), but which was developed further in Feiz (2016), Feiz and Ammenberg (2017) and Papers I and II. These steps are: (1) defining the problem to solve, meaning the decision to be decided upon or the goal of the assessment; (2) finding the alternatives to assess, meaning, the solutions possible to solve the studied problem; (3) setting up the multi-criteria assessment framework, which consists of what criteria, key areas and indicators each solution will be assessed based on; (4) gathering data and assessing each solution based on each indicator and thus making it possible to assess each key area based on the indicator scores; and (5) interpreting the results and making a synthesis judgement on the overall performance of each solution. Throughout these five steps, a life-cycle perspective is applied to reduce the risk of problem shifting or missing important characteristics that impact sustainability or feasibility (Paper I). In Figure 3, the procedure of the MCDA method of the thesis is shown. The contributions of this 
research are mainly to the process of Steps 3, 4 and 5 and are presented in the following few pages, as each step is described in detail.

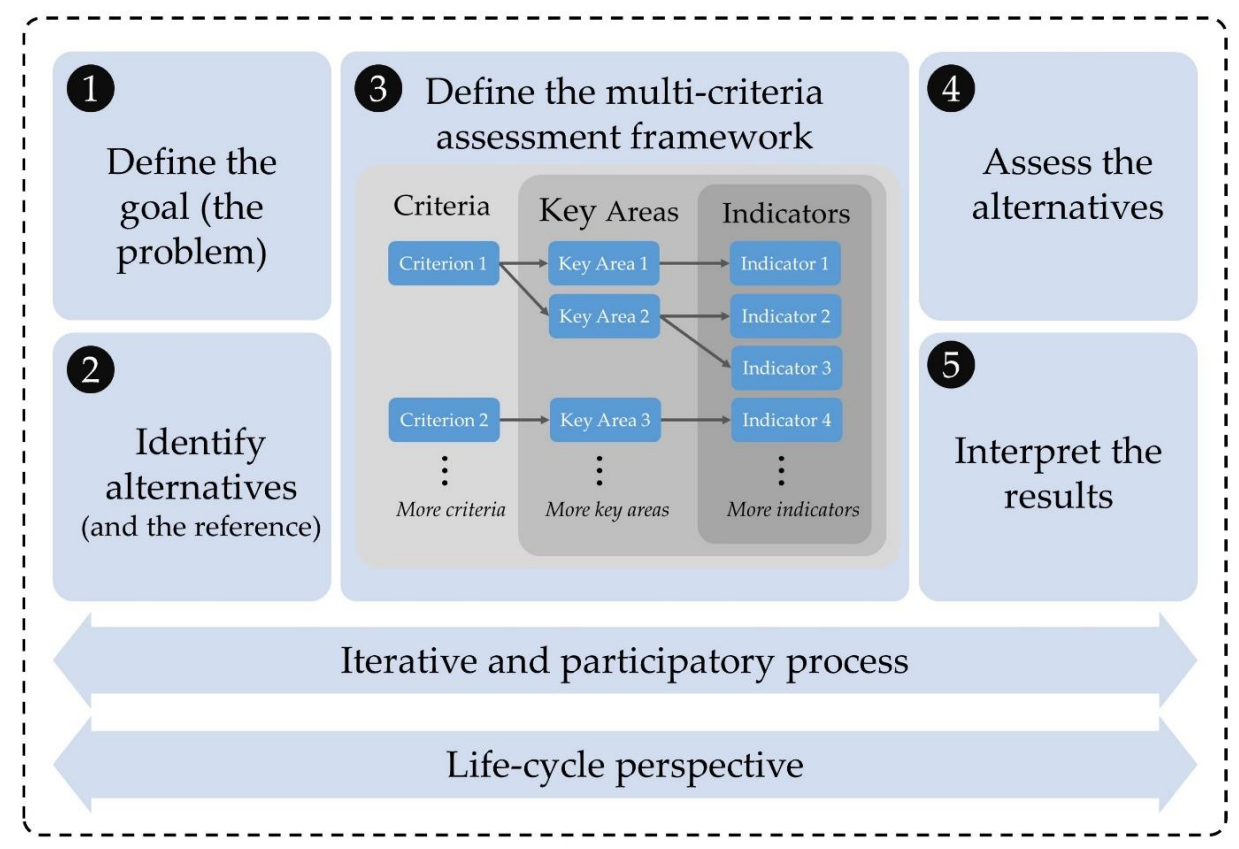

Figure 3. The procedure of the multi-criteria decision analysis method used in this thesis (Paper I).

Step 1. The importance of the first step is often neglected, as the problem or goal definition may be defined before the method of assessment is chosen and thus may seem set in stone. It may also be that the performer of the assessment believes that the problem definition is obvious and thus skips discussing this step. The problem definition originates from the sustainability-related challenge(s) that is sought to be solved, and what function(s) is needed to solve it. As such, one often asks questions about what solution is the most sustainable, how easy it is to implement and what the short-term costs are. Sometimes it is said that sustainability-related challenges are wicked (Dijk et al., 2017; Feiz and Ammenberg, 2017). This wickedness partly stems from dissensus about what the problem is (Roberts, 2000). This first step in the MCDA is thus very important, as it is where this aspect of the "wickedness" of the problem subsides, in other words, stakeholders are able to find a consensus around what the problem at hand is. For example, it may be that an organisation seeks to become more sustainable; in this case, there is a need to further specify the goal or problem. Is it the management and organisational structure that is under assessment? Is it the production processes? How to design the products? Or perhaps the purchasing of supplies? It may even be all these things, where the first assessment would be to understand where-amongst all of these areas-an intervention would give the most impact.

Step 2. After defining what problem to study, one has to determine what solutions to the problem exist, that is, what alternatives to assess. Here, one can think about all kinds of solutions, as both limited technological fixes and larger systemic changes may be possible to include in the same assessment, where 
one may contribute with less in terms of sustainability performance, and the other may be significantly more difficult to implement. In addition, it may be fruitful to include a conventional technique or the status quo as a reference alternative in the assessment (this reference may sometimes be the source of the sustainability-related challenges under study). In some cases, one may only be interested in assessing a single solution, for example, if one seeks to understand in what way and to what extent a certain solution is integrative and multi-functional.

Step 3. Next comes the setup of the multi-criteria assessment framework a structure based on Feiz and Ammenberg (2017) and further developed in Paper I; it includes defining the elements of the assessment framework, which are the criteria, key areas and indicators. These are used to assess the solutions (alternatives) defined in Step 2. The goal is to understand what metrics, characteristics and qualities should be used to define if a certain solution is more desirable than the others. Specifically, this means to understand what elements are needed to be able to state which solutions have the better sustainability performance and how feasible the solutions are to implement. Often including both generic and contextual aspects in the assessment framework is preferable because while sustainability aims to be a generic value framework, the particularities of sustainability may differ from community to community (Antwi et al., 2017) and stakeholder to stakeholder (Ekener et al., 2018). Furthermore, there is also a need to contextualize the generic aspects of sustainability to enable the assessment of a solution contribution towards the said generic aspect. For example, when assessing a certain fuel's contribution towards reducing acidification, the universal aspect of acidification may become emissions of sulphur dioxide equivalents per MJ fuel, and hence, it is contextualized to the context of comparing different fuel systems.

The process of defining the elements of the assessment framework is not entirely simple. Since sustainability largely builds on normative notions, there is no objective way to test what set of elements is the best or most optimal. This is because for norms (for example, what is right and wrong or what is good and bad) there is no objective and transcendental judge that can test whether something truly is good or bad (Habermas, 2017, p. 42). Compare this to truths of fact that may be tested in the real world. For example, if I say that the coffee machine is broken again in the common area, someone can test if this is true or not; however, if I say that inequality is morally wrong, there is no way to test whether this is true or not. Such moral truth claims must be justified in the social world, amongst interlocutors (Habermas, 2017 , p. 245). As such, I suggest that the selection of what elements to include in an assessment framework should be done in unison with stakeholders and be based on a discursive approach, departing from previous knowledge about how certain solutions interact with society and nature (Paper I). This discursive approach ought to strive for the ideal conditions of discussion (even if they are practically unobtainable), namely that (1) it is a public debate including all those affected by it, (2) the right to communicate is equally distributed, (3) it is nonviolent and non-coercive, where the force of "the better argument" reigns supreme and (4) all participants are sincere (Habermas, 2017, p. 37). An important note here is that the scientist, researcher or performer of the assessment should be considered a stakeholder and encouraged to engage in this discussion. It is also vital to allow for reflection and iteration when choosing elements. Sometimes, new information may arise in later steps of the MCDA, or new stakeholders may become 
interested and want to give their input to the assessment. This may mean that a revision of the elements is necessary, which is good, as sustainability assessment (and by extension, the assessment of multi-functional and integrative solutions) should be reflexive to cope with the interconnected and pluralistic nature of sustainability-related challenges (Dijk et al., 2017). However, there is another possible way to justify a certain selection of elements, namely using pre-defined sustainability objectives. These sets of objectives represent a certain body of people's view on what constitutes sustainability (or a particular dimension of sustainability). Thus, the assumption utilized here is that the stakeholder discussions mentioned above can be approximated through these sets of objectives. In the case of a national sustainability objective, as was the case in Paper II, the parliamentary discussion of public representatives and the formulation and constitution of objectives that stakeholders can accept are used instead of holding a stakeholder discussion including every citizen in a country (which would be practically unfeasible). Likewise, the sustainability objectives may be defined by the board of an organisation or an international body such as the UN, and the same assumption can be made. Hence, pre-defined sustainability objectives can be seen as an indirect way of accessing stakeholder opinion on what may constitute sustainability for that stakeholder group. However, if one bases their assessment framework on pre-defined sustainability objectives, the usefulness of this assessment framework depends on the validity of the objectives and how well these encompass relevant sustainability dimensions. In Figure 4, the two pathways of justifying the selection of assessment framework elements are illustrated. Often, these two ways are combined in hybrid approaches where predefined objectives are considered in the stakeholder discussions about what elements to include.

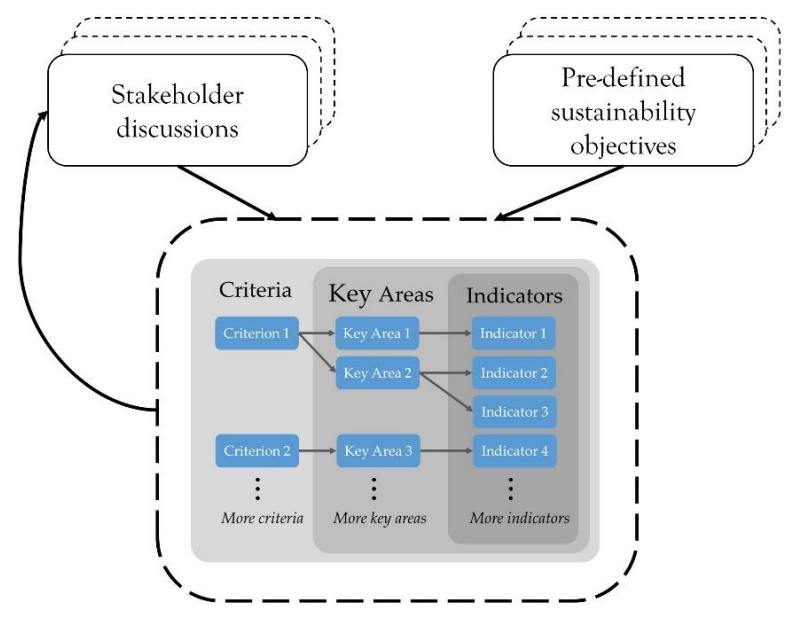

Figure 4. Suggested pathways for defining the multi-criteria assessment framework and its elements.

The features of the elements of the multi-criteria framework suggested in this thesis are presented in the order of criteria, key areas and indicators. The elements can be developed in a top-down fashion, namely, starting with criteria, then expanding these into key areas and finally indicators, which was done in the cases described in Paper I. However, one can also use a bottom-up approach starting from a set of indicators, then grouping similar indicators into key areas and finally arranging these key areas together 
to form criteria. This was done in Paper II, although the assessment framework in Paper II only included one criterion, environmental performance (in Paper II, the word "criteria" is used instead of key area; however, the criteria of Paper II are the equivalent of key areas in this thesis).

Criteria are broad and overarching categories that originate from the problem formulation and the goal of the assessment. In the context of the thesis, they often take the shape of each sustainability dimension (e.g., a criterion for good environmental performance) and a criterion covering the feasibility of implementation. In Paper I, the scale or significance of the solution's potential contribution to different sustainability domains is also highlighted as a possible criterion. In many cases, one will find that it is difficult to isolate criteria due to the interconnected nature of sustainability and the closeness of feasibility to some of the sustainability domains (e.g., economic sustainability may be linked to the feasibility of implementation). However, having overlaps between criteria is not necessarily an issue. These overlaps do, however, need to be acknowledged and be made explicit during the interpretation step (step 5), so that no unintended double counting occurs.

Next are the key areas, they define the areas of knowledge relevant to each criterion and can be seen as the middle way between the broad criteria and the detailed indicators. They make it possible for a decision-maker to get an overview of how a certain solution performs within different knowledge domains, without overloading the decision-maker with data and unprocessed information. This balancing act of defining good key areas requires one to balance between having too many key areas and having too few. Too many key areas could lead to it being difficult to thoroughly assess each key area and may make it more difficult to assess the parent criterion due to the difficulty of making multi-dimensional judgements. Too few key areas on the other hand and you risk missing central issues. There is no golden rule or approximate yardstick to use here; instead, the stakeholders included in the assessment have to perform this balancing act until a consensus is reached. There is, however, some key areas that are recommend including, or at least be discussed before their exclusion. A list of these recommendations, developed in Paper I, is found in Table 2 (a more thorough description of each key area can be found in Paper I). The key areas can also be formulated as key questions to make it easier to understand what knowledge is needed to assess each key area (Feiz and Ammenberg, 2017; Paper I). 
Table 1. A list of recommended key areas, along with some suggested key questions, to consider when assessing the sustainability performance and feasibility of integrative and multi-functional solutions.

\begin{tabular}{|l|l|}
\hline Key area & Suggested key question \\
\hline Potential scale of supply & $\begin{array}{l}\text { Can this alternative supply enough products, services (or functions) relevant } \\
\text { to contribute in a significant way to solve the considered problem? }\end{array}$ \\
\hline Potential scale of demand & $\begin{array}{l}\text { Is there significant demand, relevant to the considered problem, for the prod- } \\
\text { ucts, services (or functions) that are delivered in this alternative? }\end{array}$ \\
\hline $\begin{array}{l}\text { Greenhouse gas emissions } \\
\text { reduction }\end{array}$ & $\begin{array}{l}\text { Considering the life-cycle, is this alternative good (or better than the reference) } \\
\text { from the perspective of greenhouse gas emissions? }\end{array}$ \\
\hline Primary energy balance & $\begin{array}{l}\text { Considering the life-cycle, is this alternative good (or better than the reference) } \\
\text { from the perspective of primary energy use? }\end{array}$ \\
\hline Local and regional environ- & $\begin{array}{l}\text { Considering the life-cycle, is this alternative good (or better than the reference) } \\
\text { in regard to various local and regional environmental impacts? }\end{array}$ \\
\hline Profitability or cost-efficiency & $\begin{array}{l}\text { Considering the life-cycle, is this alternative relatively profitable; or if profita- } \\
\text { bility is not the purpose, is it cost-efficient? }\end{array}$ \\
\hline $\begin{array}{l}\text { Degree of control and com- } \\
\text { peting applications }\end{array}$ & $\begin{array}{l}\text { Considering the life-cycle, are there competing solutions to the considered } \\
\text { alternative? Can the involved actors have a reasonable degree of control over } \\
\text { the supply of relevant inputs and demand? }\end{array}$ \\
\hline Institutional feasibility & $\begin{array}{l}\text { Considering the life-cycle, is this alternative relatively supported by existing } \\
\text { and foreseeable regulations and institutional conditions? }\end{array}$ \\
\hline Technical feasibility & $\begin{array}{l}\text { Considering the life-cycle, is this alternative relatively feasible from a technical } \\
\text { perspective? }\end{array}$ \\
\hline Organizational feasibility & $\begin{array}{l}\text { Considering the life-cycle, is this alternative relatively feasibility from an or- } \\
\text { ganizational perspective? }\end{array}$ \\
\hline
\end{tabular}

The final element of the assessment framework to be presented is the indicators. The indicators are used to operationalize each key area by detailing what data is to be gathered to assess the parent key area and how this data should be assessed. The suggestion is to define one to three indicators for each key area to avoid the risk of analytical paralysis, stemming from having to gather or process too much data to systematically assess each key area (Hertwich et al., 1997).

To assess each indicator, one may use a five-grade scale consisting of 'very poor', 'poor', 'fair', 'good' and 'very good' or similar. In Paper II, it is used to score each indicator in relation to their effect on the Swedish environmental quality objectives, thus, modifications to the indicator labels were made (see Table 3). One may think of this score as a bridge between the indicators and the key areas. The scale allows one to move from the data of the indicators to a normative score and then to assessment of the key areas, thus allowing for a more easily comprehendible view of how each solution performs within each key area. While it may sound strange to assess whether an area of knowledge is good or bad, one has to remember that it is still the alternative that is being assessed. Hence, poor institutional feasibility does not mean that the knowledge about institutional feasibility is poor, but that the alternative being assessed is a poor fit to the current institutional context. The normative nature of this scale is designed to fit the normative nature 
of concepts such as sustainability and feasibility. If one would have used an objective scale, a 'high' score in a certain indicator could be good from one perspective but bad from another, and as such, the interpretation of the results would have been much less intuitive. In Table 3, an example of two scales from Paper II is shown to clarify what the scales may look like and what information they give to the performer of the assessment.

Table 2. Examples of normative scales used in the public procurement tool in Paper II.

\begin{tabular}{|c|c|c|c|c|c|}
\hline & $\begin{array}{l}\text { Large positive } \\
\text { effect }\end{array}$ & $\begin{array}{l}\text { Small positive } \\
\text { effect }\end{array}$ & $\begin{array}{l}\text { Negligible ef- } \\
\text { fect }\end{array}$ & $\begin{array}{l}\text { Small negative } \\
\text { effect }\end{array}$ & $\begin{array}{l}\text { Large negative } \\
\text { effect }\end{array}$ \\
\hline $\begin{array}{l}\text { Reduced } \\
\text { climate } \\
\text { change }\end{array}$ & $\begin{array}{l}>70 \% \text { reduction } \\
\text { compared to fos- } \\
\text { sil reference }\end{array}$ & $\begin{array}{l}21-70 \% \text { reduc- } \\
\text { tion compared to } \\
\text { fossil reference }\end{array}$ & $\begin{array}{l}0-20 \% \text { reduction } \\
\text { or increase com- } \\
\text { pared to fossil } \\
\text { reference }\end{array}$ & $\begin{array}{l}21-70 \% \text { increase } \\
\text { compared to fos- } \\
\text { sil reference }\end{array}$ & $\begin{array}{l}>70 \% \text { increase } \\
\text { compared to fos- } \\
\text { sil reference }\end{array}$ \\
\hline $\begin{array}{l}\text { Improved } \\
\text { air quality }\end{array}$ & $\begin{array}{l}\text { Significant } \mathrm{NO}_{x} \\
\text { and Particulate } \\
\text { matter emissions } \\
\text { reduction (>50 } \\
\% \text { ) during opera- } \\
\text { tion of the vehi- } \\
\text { cles. }\end{array}$ & $\begin{array}{l}\text { Significant } \mathrm{NO}_{\mathrm{x}} \\
\text { or Particulate } \\
\text { matter emissions } \\
\text { reduction (>50 } \\
\% \text { ) during opera- } \\
\text { tion of the vehi- } \\
\text { cles. }\end{array}$ & $\begin{array}{l}\text { No difference in } \\
\mathrm{NO}_{\mathrm{x}} \text { or Particu- } \\
\text { late matter emis- } \\
\text { sions compared } \\
\text { to fossil refer- } \\
\text { ence during op- } \\
\text { eration of the ve- } \\
\text { hicles. }\end{array}$ & $\begin{array}{l}\text { Significant } \mathrm{NO}_{x} \\
\text { or Particulate } \\
\text { matter emissions } \\
\text { increase (>50\%) } \\
\text { during operation } \\
\text { of the vehicles. }\end{array}$ & $\begin{array}{l}\text { Significant } \mathrm{NO}_{\mathrm{x}} \\
\text { and Particulate } \\
\text { matter emissions } \\
\text { increase (>50\%) } \\
\text { during operation } \\
\text { of the vehicles. }\end{array}$ \\
\hline
\end{tabular}

Step 4. This step is straightforward, but often requires a lot of time and effort. Here, one gathers data in order to assess each solution-indicator couple and assesses them. Data gathering for this assessment can be done in multiple ways, everything from literature or document studies to interviews, field experiments or simulations. This means that the effort and resources needed are tied to the relationship between the quantity and quality of knowledge needed and the quantity and quality of knowledge readily available. If one needs to perform extensive field experiments, simulations, interviews or document studies, this will require extensive resources and time. If one "only" has to gather and structure already available knowledge, less time and resources are needed (although this may still present a considerable challenge, depending on the availability of this knowledge). In the cases found in Paper I, data was gathered mainly through literature studies when it came to indicators for sustainability performance, and primarily through interviews when it came to feasibility aspects. In Paper II, data was gathered solely through a literature study (although feasibility aspects were not included in this study). However, one may imagine cases where data is entirely missing for certain solution-indicator couples, and therefore a sub-study like a simulation or field experiment would be necessary to fill this gap, although in some cases, the identification of such a research gap could be a sufficient result.

Step 5. The final step of the MCDA method proposed in this thesis is the interpretation of the results. When finishing step four, one is left with several results for each solution-indicator couple and 
based on the scales defined for each key area, an assessment within each key area. However, an interpretation of these results is required to be able to judge which solution is preferred in a particular context. Here, the so-called hard MCDA often applies stakeholder weighing and some form of algorithm to decide which solution is optimal, see, e.g., Diaz-Balteiro et al., (2017) and Kumar et al., (2017) for a review of such methods. The soft MCDA, and as such, the method presented here, favours a discursive approach. The goal of the discussion is not to find an optimal solution but a consensus, in other words, a solution that everyone can accept. Indeed, an optimum is seldom possible to find due to the value plurality of the assessment and the different stakeholders' value orientations (Martinez-Alier et al., 1998). Furthermore, different solutions may perform well in different key areas, meaning that synergies, trade-offs and conflicts of interest are common. This leads to the second reason why a discursive approach is favoured, acceptance. If one hides the conflicts between different key areas, goals and value orientations behind surveys and algorithms, it is much less likely that the stakeholders will accept the outcome of this step, as it may lack transparency. If one instead opens a discussion to solve conflicts and work towards a consensus alternative, the acceptance of the assessment may become higher. In addition, such discussion may also change the value orientation of the stakeholders towards becoming more altruistic because they gain more insight into other stakeholders' perspectives (Raymond and Kenter, 2016).

The idea of a discursive approach to deciding which alternative is the preferred one also ties back to the discussion about how to select relevant framework elements in step three. Namely, this decision is also a moral decision, for example, the decision that a hypothetical alternative $q$ is the preferable alternative is a moral truth claim, which that can only be justified in the social world, which is discursive in nature (Habermas, 2017, pp. 245-247). The question about which alternative is the most sustainable while also being feasible to implement (which is a question commonly posed in Step 1 of the MCDA) can only be answered with a moral truth claim since it requires knowing the relative importance of the different key areas with respect to each other. However, since indicators (and as such key areas) may build on truths of facts, for example, how much of a certain pollutant is emitted, these moral truth claims may in part build upon a positivistic epistemic core, which is susceptible to fallibility (Habermas, 2017, p. 38). This means that judging the sustainability performance of and the feasibility to implement an alternative is fundamentally a discursive decision, but one affected by the epistemic context. This is a context that is represented by the score of the indicators and which may change over time. To summarize, this thesis puts forth the discursive approach as the favoured one to interpreting and judging the results of MCDAs, the reason being that the decision of choosing which solution is preferable from a sustainability and feasibility perspective is a process that includes moral truth claims, whose validity can only be tested through discussion.

Some may still be unconvinced, perhaps arguing that other options, such as individual weighing ${ }^{9}$, can be seen as a substitution for discussion, and one that may be faster and avoid "unnecessary" conflicts. My answer to this argumentation can be summed up by a quote from Strauss (Strauss, 1953, p. 310):

\footnotetext{
${ }^{9}$ The practice whereby each stakeholder involved in the decision weighs the importance of each criterion in some manner, either by cardinal or ordinal scales.
} 
"Speculation, being essentially private, is concerned with the truth without any regard for public opinion. But national measures or political problems do not primarily concern truth or falsehood [e.g. objective truths, or truths of fact]. They relate to good or evil. They relate to peace and mutual convenience, and their satisfactory handling requires unsuspecting confidence, consent, agreement and compromise." Individual weighing is a private affair and is in this case equal to speculation since there is no objective truth to be found for the relative importance of key areas. Choosing which alternative is preferable from a sustainability perspective is akin to a political problem as it requires making explicit one's own reasons to favour some sustainability domain over others. Furthermore, politicians or public authorities are often involved as stakeholders in systemic change, and as such, the political nature of this step is even more evident. Therefore, to handle this step in a satisfactory way, "unsuspecting confidence, consent, agreement and compromise" is necessary, which can only be found in a discursive approach. While such an approach may be more time consuming and more difficult, this cannot be the reason why one should at least not attempt the discursive approach.

Now, when presented with two options, a natural response may be to ask, what about if I do both? What about a discursive approach to finding quantitative weights? Such an approach is certainly possible, and is the approach put forth in Paper II. The suggested approach of that paper is for the procuring organisation to hold discussions on how to quantitatively weigh the environmental performance in relation to the price of incoming tenders and how to weigh each key area in relation to other key areas. With this approach, the stakeholder group comes to a consensus around what the quantitative weights should be for each criterion, key area or indicator (depending on what level one aggregates from). This enables one to apply hard MCDA methods to find the preferable option based on these weights. Sometimes, such quantitative and algorithmic assessment methods may be preferable due to the need for aggregation or practical applicability. This was the case in Paper II, since the public procurement directives of the EU proclaim that the procurer has to either choose the alternative with the lowest price or the most economically advantageous alternative (Lundberg and Bergman, 2011). This means that one needs to aggregate values into economic value; otherwise, one cannot claim low price nor economic advantage. The hybrid approach of group weighing does overcome issues of acceptance and transparency since everyone can be involved in the weighing process. It also avoids issues of private speculation because value orientations and reasons must be made explicit to hold merit in these discussions. However, there are some issues with this approach, which is why the fully discursive approach is favoured above the group weighing approach if the choice is possible. First, the weights that may come from such a group weighing process may be misused in other contexts. They may be reified and be seen as the definitive weights for the relative (or absolute) importance of these sustainability domains. For example, one group may produce weights for a certain decision and at a later stage-in order to save time-some individual from an organisation that took part in the original discussion uses those weights for another decision instead of forming a new group. This reification is problematic since these weights are only valid for the particular epistemic (what knowledge to consider) and organisational context (what actors to include) of the decision for which they were justified. Other decisions have other contexts, which requires other knowledge and other constellations of actors; therefore, the definition of group weights brings with them the inherent risk that they may 
be misused. Second, the aggregation of criteria, key areas or indicators through quantitative weighing goes against the value pluralistic nature of sustainability decisions, as the values behind the criteria, key areas and indicators are incommensurable (Martinez-Alier et al., 1998). The group weighing approach, therefore, risks turning the assessment from multi-criteria decision analysis to single-criterion decision analysis.

Now, when all five steps of the MCDA are completed, the wickedness and complexity of the sustainability-related challenge at hand has been reduced. There should-when this stage is reached-be a consensus on what the problem is and how it should be solved (or what solutions contribute towards solving it in the preferred way), thereby providing crucial input to the continuation of the implementation process. However, understanding the sustainability values and the feasibility of a certain solution is not enough for it to become implemented. Other aspects play a part in the process of implementation, and in the next chapter, the internal capacities for collective action and their importance to the process of implementing integrative and multi-functional solutions are described and discussed. 


\section{5 \\ Lessons on facilitation}

To implement integrative and multi-functional solutions, collaboration and collective actions will be necessary. Since the sustainability-related challenges that these solutions seek to address are often complex or wicked, consensus through discussions and collaboration needs to be formed (Roberts, 2000). Furthermore, it is rare that a single actor has the authority and resources to implement integrative and multifunctional solutions on their own. Finally, the functions-and thus the values-of these solutions are spread across different actors, meaning that proper implementation may require the costs to be spread in a similar fashion to how the values are spread. All these aspects mean that integrative and multi-functional solutions are solutions that concern many different actors and require further collaboration and more direct collective action than what can be expected of other conventional and more single-minded solutions.

As presented in the introduction and Chapter 2, this thesis draws ideas from the field of industrial symbiosis to understand how collective action towards implementing integrative and multi-functional solutions can be facilitated. Specifically, the focus is on how the internal capacities of networks to engage in collective action can be strengthened. Therefore, the theory of institutional capacity building (Boons et al., 2011; Boons and Spekkink, 2012; Healey et al., 2003) is employed as a way of understanding how this capacity can be strengthened. As was stated in Chapter 2, institutional capacity is built along the three dimensions of relational resources, knowledge resources and mobilization capacity (Boons et al., 2011; Boons and Spekkink, 2012; Spekkink, 2016, 2015). All three dimensions can be built through a few basic interactions put forth by Boons et al. (2014). The theory of institutional capacity building, and these basic interactions, were applied to guide a facilitative intervention in Norrköping, Sweden (research journey three from Chapter 3) aimed at facilitating the development of collaborative biogas solutions. Throughout three workshops, actors met to discuss and plan how biogas solutions could be facilitated in Norrköping. These actors included civil servants from the municipality, the municipal wastewater treatment plant, and the regional authority as well as actors from biogas producing companies, biofertilizer companies, a paper mill, waste management companies and a zoo. The workshops were split up during the spring of 2019, with six-week intervals between each workshop. In Table 4, an overview of the basic interactions suggested by Boons et al. (2014) can be seen, alongside descriptions of how interactions held in the workshop series in Norrköping were performed. 
Table 3. The interactions suggested by Boons et al. (2014) as interactions that build institutional capacity within networks. How these interactions were performed in the Norrköping workshop series is also briefly described (Paper III).

\begin{tabular}{|c|c|c|}
\hline Interaction & Description & Presence in the Norrköping workshop series \\
\hline Orientation & $\begin{array}{l}\text { Exploration and negotiation between } \\
\text { actors that help them to develop com- } \\
\text { mon definitions of problems and so- } \\
\text { lutions as well as strengthen relations } \\
\text { between them. }\end{array}$ & $\begin{array}{l}\text { Most of the first workshop focused on orientation, } \\
\text { both to explore the subject at hand and for the partic- } \\
\text { ipants to familiarize themselves with each other. This } \\
\text { was done through both roundtable discussions and } \\
\text { informal discussions. }\end{array}$ \\
\hline Planning & $\begin{array}{l}\text { Formulations of concrete plans to re- } \\
\text { alize the implementation of a certain } \\
\text { common solution. }\end{array}$ & $\begin{array}{l}\text { The final workshop aimed to plan ways of overcom- } \\
\text { ing various identified barriers and exploit opportuni- } \\
\text { ties to implement biogas solutions. }\end{array}$ \\
\hline $\begin{array}{l}\text { Feasibility } \\
\text { studies }\end{array}$ & $\begin{array}{l}\text { The process of performing joint re- } \\
\text { search with the aim of exploring the } \\
\text { feasibility of implementing a certain } \\
\text { common solution. }\end{array}$ & $\begin{array}{l}\text { A potential study focusing on the potential to pro- } \\
\text { duce and sell upgraded biogas in Norrköping munici- } \\
\text { pality was performed as a type of feasibility study. } \\
\text { This was done in between workshops one and two. }\end{array}$ \\
\hline $\begin{array}{l}\text { Implemen- } \\
\text { tation }\end{array}$ & $\begin{array}{l}\text { Actors work together to implement a } \\
\text { common solution that they have pre- } \\
\text { viously planned. }\end{array}$ & - \\
\hline $\begin{array}{l}\text { Influencing } \\
\text { other actors }\end{array}$ & $\begin{array}{l}\text { Activities performed by one actor to } \\
\text { influence another actor within the } \\
\text { network to make them more likely to } \\
\text { engage in future collective action. }\end{array}$ & $\begin{array}{l}\text { Informal discussions in and around the workshop se- } \\
\text { ries may have had this effect as actors sought to come } \\
\text { up with new ways to collaborate and to bring more } \\
\text { relevant actors into the network. }\end{array}$ \\
\hline Declaration & $\begin{array}{l}\text { An action where an actor, or several } \\
\text { actors, formally declare(s) the inten- } \\
\text { tion to act to solve a common prob- } \\
\text { lem, often involving the signing and } \\
\text { publication of formal documents. }\end{array}$ & - \\
\hline $\begin{array}{l}\text { Establishing } \\
\text { new organi- } \\
\text { zations }\end{array}$ & $\begin{array}{l}\text { Actors join together and establish a } \\
\text { new organization devoted, at least in } \\
\text { part, to furthering the industrial sym- } \\
\text { biosis network. }\end{array}$ & - \\
\hline $\begin{array}{l}\text { Strategic } \\
\text { visioning }\end{array}$ & $\begin{array}{l}\text { Actors establish joint strategic visions } \\
\text { where they describe their common } \\
\text { goals. }\end{array}$ & - \\
\hline $\begin{array}{l}\text { Influencing } \\
\text { the context }\end{array}$ & $\begin{array}{l}\text { Activities performed by one or several } \\
\text { actors with the aim of influencing the } \\
\text { contextual factors surrounding the } \\
\text { network. }\end{array}$ & - \\
\hline
\end{tabular}


As can be seen in Table 4, the workshop series included four of the basic interactions proposed by Boons et al. (2014). These were orientation, planning, feasibility studies and influencing other actors. The participants of the workshop had little to no previous relations with each other. Therefore, much of the first and second workshop series was about orientation. This served a dual purpose in both orienting the participants with each other and with the subject, as different participants had different knowledge levels, but none had knowledge about all the different factors that influence biogas systems' development in Norrköping municipality. The orientation was mainly done through roundtable discussions with the aim of mapping the current situation surrounding biogas systems in the municipality. Before the second workshop, a feasibility study was performed that assessed the biogas potential in Norrköping municipality and the feasibility of different biogas systems. The feasibility was further discussed at the second workshop, and a few key barriers and opportunities were identified. From these key barriers and opportunities, a list of prioritized actions was distilled and presented at the third workshop, which focused on who could take the lead on these prioritized actions and how they could be realized. This final workshop would fall into the planning interaction in Boons and colleagues' (2014) list of interactions.

From observations made during and after the workshop series, and through a survey sent out to participants, it was clear that institutional capacity had been built through these interactions (Paper III). Regarding relational resources, most respondents stated that the workshop series had led to new relations forming ( $89 \%$ ) or the strengthening of old relations (67\%). As for knowledge resources, the survey followed a similar trend, with $90 \%$ of respondents stating some increase of knowledge. Of these, $33 \%$ stated a large increase in knowledge regarding biogas solutions in Norrköping. As for mobilization capacity, respondents answered that the workshop series had increased their interest and willingness to act to develop biogas solutions in Norrköping. Moreover, the establishment of leaders for how to overcome each key barrier and exploit each key opportunity should also help to increase the mobilization capacity of the network. Furthermore, some initiatives are already underway towards the implementation of biogas solutions in Norrköping, such as further meetings, funding applications and focused feasibility studies. A minor conclusion from the Norrköping study was that universities might play key roles in setting up arenas that build institutional capacity. This is because universities have the financial resources, relational networks and knowledge required to create these arenas (Paper III). However, it is unlikely that universities can sustain the network, as they are generally not involved in the building or operation of integrative and multi-functional solutions. In the workshops in Norrköping, the local authority (the municipal organisation) instead took the role of sustaining the network. Previous literature has highlighted the possibility of municipalities working as network brokers in industrial symbiosis networks due to their inherent legitimacy, relational network and interest in local sustainable development and business performance (Burström and Korhonen, 2001).

Another contribution was made to the use of the theory of institutional capacity building. In Paper III, it was shown that the theory could be used to guide interventions aiming to facilitate the implementation of integrative and multi-functional solutions (and industrial symbiosis development in general). Previously, the theory had been used to investigate and analyse historical programmes and developments 
to understand what actions and events influenced the industrial symbiosis development and how institutional capacity was built by these actions and events (Abreu and Ceglia, 2018; Boons and Spekkink, 2012; Spekkink, 2015, 2013). The study in Paper III shows that it is possible to utilize the theory to guide interventions and give insight into the process of developing such facilitative interventions. Furthermore, the theory can also be used to evaluate how interventions affected the internal capacities of networks and help to improve the effectiveness of any forthcoming potential interventions in a formative manner. This contributes to future interventions so they may have a larger impact, and that the chance of integrative and multi-functional solutions being implemented is increased. 


\section{6}

\section{Methodological discussion}

This chapter is dedicated to discussing different topics of relevance to all the research performed and described in this licentiate thesis. The first topic of discussion is how the MCDA method presented in Chapter 4 fits into the process of implementing integrative and multi-functional solutions. Throughout the thesis the importance of broad, relevant and systematic assessments of integrative and multi-functional solutions have been touched upon in order to motivate why they should be implemented. However, this is a simplification of the relation between the MCDA method of the thesis and the process of implementation. In practice, the MCDA method can be further integrated within the implementation process. For example, the knowledge gained throughout the process of completing the MCDA and from the results of MCDAs, contributes to showing the many values that an integrative and multi-functional solution may have, thereby possibly increasing the willingness to implement such solutions. This can also be seen in the light of institutional capacity building as enhancing the knowledge resources of the participants. Furthermore, the participatory and discursive aspects of the MCDA method require stakeholder groups to form around the assessment. These groups may be able to play key roles in the continued implementation process after the assessment is done, thereby strengthening the relational resources within that group. The stakeholder discussions and group judgements needed to define the goal, identify alternatives, define the assessment framework and finally judge which alternative is preferable may also help the stakeholder group to align their norms, values, language and visions (Ranger et al., 2016; Raymond and Kenter, 2016), which increase their mobilization capacity.

An important note may also be that the process of implementing integrative and multi-functional solutions is in practice an iterative approach, which does not necessarily have to follow the primacy of thought over action. For example, a group of actors may form a network around a particular idea and attempt to realize it. They then hit some roadblocks and are forced to analyse, assess and evaluate the idea, perhaps in a rudimentary way at first. After some thought, another try is made, which is more successful but does not materialise in any tangible outputs. Other actors may be invited to fill the necessary roles and functions that the network had been missing, and perhaps another try is made. However, this time the institutional context may not be favourable enough to allow implementation, so the network does a more thorough assessment to show the value of the idea in hopes of influencing other actors and changing the context. This may continue for quite some time-with various iterations of group members, various assessments and various implementation attempts of varying intensity-before an actual tangible 
systematic change is implemented. As such, the MCDA method may become relevant very early in the implementation process as a screening tool to select a few interesting ideas with which to continue working. On the other hand, it may be used as decision support and motivation for the actual decision to implement a solution, or it may be used to assess how a certain solution performs after its implementation.

When it comes to assessments as decision support tools, the MCDA method presented here is, of course, not the only method. Another method used to capture a solution's broader set of benefits and costs, and that is commonly used to assess policy measures and large infrastructure investments, is costbenefit analysis (Boardman et al., 2018). In a cost-benefit analysis, the aim is to translate all tangible and intangible costs and benefits into monetary terms. Most impacts on sustainability domains, such as pollution, ecosystem degradation, equity change or health matters, are benefits for which there exists no market and thus no direct pricing mechanisms to use to convert these into money. In these cases, various survey methods or indirect pricing mechanism are employed to try to gauge the monetary value of these benefits (Boardman et al., 2018). Through this, one can eventually reach a monetary value for the costs and benefits of the solution, and if the benefits outweigh the costs, one implements the solution (a somewhat simplified description). However, there are a few reasons why this approach was not chosen in this particular thesis. First, cost-benefit analysis is a purely quantitative method, which means that benefits that cannot be quantified (or require too many resources to enable their quantification) in monetary terms are left out of the analysis. Even if these benefits are qualitatively discussed and explicitly omitted (from the quantitative assessment), decision-makers and result interpreters may only focus on the result and thus miss other important non-quantifiable benefits. Furthermore, cost-benefit analyses tend to only include economic feasibility when assessing the feasibility of solutions, which means that the significance of this method for the implementation process is lower than that of methods that can integrate a broader set of feasibility aspects. Finally-and most importantly-I argue that cost-benefit analysis is insufficient as decision support when it comes to decisions with the aim of contributing to sustainable development. This insufficiency comes from the value pluralism inherent to sustainable development (see, for example, the description of sustainable development in United Nations, 1987). Within value pluralism, different things that one may find valuable are inherently separate, and there exists no one value that all other values may be expressed in terms of. Therefore, these values cannot be properly expressed solely in economic terms (Martinez-Alier et al., 1998). In addition, values are conditional in value pluralism, meaning that the relative importance of values depends on the context and case where these values are employed. For example, imagine a simple hypothetical case where a choice between $a$ and $b$ is based on two values, environmental harm and price. Something is deemed more valuable if it has a lower price and does less environmental harm. Depending on how large the difference in environmental harm is and what type of harm it is, the relative importance of environmental harm and price may differ, the same for changes in the price. While conditional values are compatible with cost-benefit analysis if these are re-measured for each cost-benefit analysis, it is all too common to use prices calculated for entirely different contexts when performing such analysis. For these reasons, the cost-benefit method is not enough to satisfy the aim and research questions (1 and 2) of this thesis and, as such, was not chosen. However, depending on the 
indicators chosen, results and knowledge gained through cost-benefit analysis may be used within the framework of the MCDA method. For example, if one seeks to show the economic value of a certain solution, cost-benefit analysis is a suitable method to employ in order to assess that particular indicator. While this has not been done within this thesis, it is perfectly possible.

In Chapter 3, the reasons why the research chose a transdisciplinary research approach and the benefits of this approach to the thesis were discussed. However, a transdisciplinary research approach does not only bring with it positive traits. The fact that the research questions and research objects are chosen from real-world challenges often leads to favouring usability and practical criteria of viability when evaluating the results. This can, in turn, lead to a preference for showing that something works in this specific case, rather than answering why something works or if it works in general. Furthermore, transdisciplinary research tends to produce case-specific knowledge because the primary goal is often to solve-or contribute towards solving-the specific real-world challenge from which the research originated. As such, it can prove difficult to generalise the results and improve upon disciplinary theories. If such general insights are put forth, it is often due to insights gained from combining theories from traditionally separate fields, for example, business models and industrial ecology (Short et al., 2014), organisational theory and industrial ecology (Magnusson et al., 2019) and theories of the firm and corporate sustainability (Lozano et al., 2015). This dependency on case-specific results could be part of the reason why transdisciplinary science often has trouble generating high scientific impact in bibliometric terms, a challenge noted by Brandt et al. (2013). This challenge of transdisciplinary science can also be seen in the research performed in this thesis. Each research journey (described in Chapter 3) originated from questions and challenges of realworld actors, and ultimately the practicality and usability of the results were often prioritized higher than generalisability or transferability. Instead, general and abstract insights were sought after on the methodological and theoretical level, which is why the thesis mainly deals with methodology and method developments.

However, one should not forget that there are reasons why a transdisciplinary research approach was needed in this research. The transdisciplinary approach allowed the researchers to understand societal needs and discuss necessary value judgements. In research about human society, there are always value judgements to be made, and in research about sustainability, this is especially obvious. For example, one has to decide what contributes to sustainable development in specific situations. In addition, it is common that conflicts between different domains of sustainability occurs, and in these cases, one needs to resolve these conflicts through value judgements. As such, the access to other stakeholders' input becomes crucial in order to integrate these value judgements in a valid way; otherwise, the researchers' own value orientation may skew the results, or stakeholders may perceive the result as illegitimate and reject its recommendations.

Furthermore, the involvement of stakeholders throughout the research process means that the results produced have a high transparency to stakeholders, since key concepts, assumptions, methods and value judgements have been developed or made in unison with stakeholders. As such, it is often easier for stakeholders to use and accept the results of transdisciplinary research (Lang et al., 2012). Moreover, 
because the research questions often originate with some (or all) of the involved stakeholders, the research has high relevance to these actors, and as such, they are more likely to act on the result.

However, due to the integration between different disciplines and between scientists and non-scientists, transdisciplinary science may have even more fundamental methodological challenges than previously discussed. Since transdisciplinary science builds a "will to integrate" where commonly the idea is that the synthesis of different knowledge domains, methods and theories will grant new knowledge, one often has to deal with conflicting epistemologies and ontologies (Donaldson et al., 2010; Klenk and Meehan, 2015). This makes it very difficult to judge the quality of transdisciplinary research, because some parts of the research must be evaluated on, for example, constructivist grounds, while others must be evaluated on positivistic grounds. For example, in the multi-criteria decision analysis of this thesis, the data used to assess the indicators may be emissions from a certain industry, which is dealt with in a positivistic manner, but it may also be reflections on the suitability of existing infrastructure to accommodate a new socio-technological system, which builds on constructivist epistemology. This presents a challenge because the quality of constructivist science is evaluated on different grounds than positivistic science (Guba and Lincoln, 1989). For example, it becomes difficult to talk about validity and generalisability in the classical natural science sense when it comes to constructivist science. Validity-that ideas reflect what occurs in the real world-faces the issue that there cannot be any non-human knowledge about the real world upon which to test the validity of social constructs. True generalisability, on the other hand, is impossible because of the assumption that worldviews are constructed between individuals, which means that true generalisability is impossible because of the possibly infinite number of different worldviews that may exist. In addition, the alluring idea of objectivity must be dismissed with a constructivist approach since knowledge is built between interacting subjects, and thereby knowledge is inherently subjective. As the main contributions of this thesis are constructivist (e.g., the discursive approach to indicator selection and the workshops that built institutional capacity), the discussion that follows on the quality of this research will be from a constructivist perspective.

The discussion will be based around three of the four criteria for evaluating quality in Guba and Lincoln (1989), namely transferability, dependability and confirmability ${ }^{10}$. Guba and Lincoln (1989) explain that there are some parallels between these criteria and classical positivistic criteria (i.e., validity, objectivity and generalisability). The first criteria, transferability, may be seen as a parallel to generalisability as it deals with what contexts and conditions research findings may be transferred to and used in. Here, a hallmark of high quality is that it should be clear under what conditions the methods, theories or results can be transferred from one person, group or context to another (Guba and Lincoln, 1989). Descriptions of the contexts and participants in each study has been given to ensure this, along with reflections on what the possible limits of the methodology presented in the thesis are. In addition, underlying assumptions that are known to the author of this thesis have also been stated to aid readers in understanding the limits of its transferability. Moving on to dependability, which is one of two the parallel criteria to objectivity (the

\footnotetext{
${ }^{10}$ The fourth criterion is credibility and is excluded from this discussion due to its focus on the evaluator's perception of how credible the work is. As such, the entirety of the thesis is the basis for evaluating this criterion.
} 
other being confirmability), all constructivist research will depend on the input of the participants of the research, however, the criteria of dependability is not evaluated based on whether the research is dependent or not. Instead, the evaluation is done qualitatively based on how the research is dependent on its participants (Guba and Lincoln, 1989). Indeed, in transdisciplinary research, the fact that participants actively influence the research is seen as a strength and an important part of the collective learning that is so desirable in such research (Pohl and Hirsch Hadorn, 2008). In order to evaluate the research dependability, the research needs to be transparent when it comes to how the research was affected by each participant (Guba and Lincoln, 1989). To this end, Guba and Lincoln suggest keeping a dependability journal to keep track of how different participants influenced the research. This was not done to its full extent, although for key assumptions, methodological choices and collective definitions, it is stated how these were reached and on what logical grounds. While a more thorough dependability journal would have made it easier for readers to evaluate the research's dependability, it is argued that what is presented in the thesis still provides enough insight to understand how the research depended upon its participants. Finally, confirmability concerns the ability of readers to understand where data was found and how it was processed. It is the second parallel criterion to objectivity. For this criterion, one should refer to the references made throughout the thesis and its appended papers. These detail where data was gathered, and the origin of theories and methods applied. How processing and analysis of data were done is at the core of this thesis, namely the multi-criteria decision analysis method, which has been thoroughly presented and discussed. 


\section{7 \\ Conclusions and Outlook}

Integrative and multi-functional solutions will play an important part in sustainable development through their ability to contribute towards different sustainability-related challenges simultaneously and the synergistic benefits that may come from linking traditionally separate organisations together. However, assessing to what extent solutions are integrative and multi-functional requires assessment methods capable of including a variety of knowledge domains, both quantitative and qualitative data, and dealing with differing goals and value frameworks. This thesis suggests an MCDA method as a way of systematically assessing to what extent solutions are integrative and multi-functional, in other words, how large their impact on various sustainability domains is and how they may be implemented. This assessment builds on traditional MCDA procedure with contributions mainly to the steps of selecting criteria, key areas and indicators as well as how to comparatively judge alternatives. In these steps of the assessment procedure, the MCDA of this thesis favours a discursive approach, contributing with motivations for this and examples of how decision support tools may be designed to enable a comparative and discursive judgement. As for the process of selecting indicators by which to assess integrative and multi-functional solutions, the thesis puts forth two pathways for this, using stakeholder discussions, or operationalising pre-defined sustainability objectives. A mix of both pathways is also a viable alternative.

If one is able to come to a consensus about what solution is deemed preferable to continue the implementation process with, other challenges of implementing said solution still remain. Because of its integrative and multi-functional nature, successful implementation usually requires the collaboration of several actors. Interventions aimed at increasing the internal capacities of networks of actors to engage in collective action may be performed to facilitate such collaboration. Here, the theory of institutional capacity building promises to be a good support when designing and performing the formative evaluation of such interventions. The theory of institutional capacity building stipulates that the capacity of networks of actors to engage in collective actions is built along three dimensions: relational resources, knowledge resources and mobilization capacity. Furthermore, several interactions have been suggested in the literature to build institutional capacity, and while this thesis did not include studies of all of them, the interactions of orientation, planning, influencing other actors and performing feasibility studies were seen to influence institutional capacity in a positive manner. In this area, the thesis contributed with insights into how institutional capacity building can be used as a guide to both designing and evaluating interventions aimed at facilitating the implementation of integrative and multi-functional solutions. As such, actors 
who seek to facilitate the implementation of integrative and multi-functional solutions may draw inspiration from the way interactions were performed and how the intervention was evaluated when designing their own interventions.

There are some questions, looking at the continuation of this research, that remain somewhat unexplored. For example: how can the assessment of integrative and multi-functional solutions aid the implementation of such solutions? One may imagine that a systematic assessment of a solution would ease the decision of whether to implement a solution or not. Furthermore, such an assessment may favour integrative and multi-functional solutions because their many functions are captured. However, performing an assessment of the kind presented in this thesis requires a lot of knowledge and time, something that might slow down the process of implementation. Moreover, it is not entirely clear what type of knowledge is needed-and how it should be presented-when it comes to stimulating networks of actors to engage in collective actions. As such, a potential future study would be to perform an MCDA on a specific integrative and multi-functional solution where the actors needed for its implementation are already (somewhat) known and the network established. Thus, one may be able to see the effects of such an assessment on the decision-making process and infer how such knowledge is best used.

In addition, much remains to be studied about the use of the theory of institutional capacity building to guide the design and evaluation of industrial symbiosis interventions. The study in Norrköping was only able to state what dimensions had been affected and glean how they might have been affected. More research into how to better capture the changes in institutional capacity is needed, for example, in order for a comparison between different interventions and interactions to be possible. 


\section{References}

Abreu, M.C.S. de, Ceglia, D., 2018. On the implementation of a circular economy: The role of institutional capacity-building through industrial symbiosis. Resources, Conservation and Recycling 138, 99-109. https://doi.org/10.1016/j.resconrec.2018.07.001

Antwi, E.K., Owusu-Banahene, W., Boakye-Danquah, J., Mensah, R., Tetteh, J.D., Nagao, M., Takeuchi, K., 2017. Sustainability assessment of mine-affected communities in Ghana: towards ecosystems and livelihood restoration. Sustain Sci 12, 747-767. https://doi.org/10.1007/s11625-017-04749

Ashton, W., 2008. Understanding the Organization of Industrial Ecosystems. Journal of Industrial Ecology 12, 34-51. https://doi.org/10.1111/j.1530-9290.2008.00002.x

Blanc, D.L., 2015. Towards Integration at Last? The Sustainable Development Goals as a Network of Targets. Sustainable Development 23, 176-187. https://doi.org/10.1002/sd.1582

Blok, V., Hoffmans, L., Wubben, E.F.M., 2015. Stakeholder engagement for responsible innovation in the private sector: critical issues and management practices. Journal on Chain and Network Science 15, 147-164. https://doi.org/10.3920/JCNS2015.x003

Boardman, A.E., Greenberg, D.H., Vining, A.R., Weimer, D.L., 2018. Cost-benefit analysis : concepts and practice, Fourth Edition. ed. Cambridge University Press.

Boons, F., Chertow, M., Park, J., Spekkink, W., Shi, H., 2017. Industrial Symbiosis Dynamics and the Problem of Equivalence: Proposal for a Comparative Framework. Journal of Industrial Ecology 21, 938-952. https://doi.org/10.1111/jiec. 12468

Boons, F., Spekkink, W., 2012. Levels of Institutional Capacity and Actor Expectations about Industrial Symbiosis. Journal of Industrial Ecology 16, 61-69. https://doi.org/10.1111/j.15309290.2011.00432.x

Boons, F., Spekkink, W., Jiao, W., 2014. A Process Perspective on Industrial Symbiosis. Journal of Industrial Ecology 18, 341-355. https://doi.org/10.1111/jiec.12116

Boons, F., Spekkink, W., Mouzakitis, Y., 2011. The dynamics of industrial symbiosis: a proposal for a conceptual framework based upon a comprehensive literature review. Journal of Cleaner Production 19, 905-911. https://doi.org/10.1016/j.jclepro.2011.01.003

Brandt, P., Ernst, A., Gralla, F., Luederitz, C., Lang, D.J., Newig, J., Reinert, F., Abson, D.J., von Wehrden, H., 2013. A review of transdisciplinary research in sustainability science. Ecological Economics, Land Use 92, 1-15. https://doi.org/10.1016/j.ecolecon.2013.04.008

Burström, F., Korhonen, J., 2001. Municipalities and industrial ecology: reconsidering municipal environmental management. Sustainable Development 9, 36-46. https://doi.org/10.1002/sd.154

Diaz-Balteiro, L., González-Pachón, J., Romero, C., 2017. Measuring systems sustainability with multicriteria methods: A critical review. European Journal of Operational Research 258, 607-616. https://doi.org/10.1016/j.ejor.2016.08.075

Dijk, M., de Kraker, J., van Zeijl-Rozema, A., van Lente, H., Beumer, C., Beemsterboer, S., Valkering, P., 2017. Sustainability assessment as problem structuring: three typical ways. Sustain Sci 12, 305317. https://doi.org/10.1007/s11625-016-0417-x

Doménech, T., Davies, M., 2011. The role of Embeddedness in Industrial Symbiosis Networks: Phases in the Evolution of Industrial Symbiosis Networks. Business Strategy and the Environment 20, 281296. https://doi.org/10.1002/bse.695

Donaldson, A., Ward, N., Bradley, S., 2010. Mess among Disciplines: Interdisciplinarity in Environmental Research: Environment and Planning A. https://doi.org/10.1068/a42483

Ekener, E., Hansson, J., Larsson, A., Peck, P., 2018. Developing Life Cycle Sustainability Assessment methodology by applying values-based sustainability weighting - Tested on biomass based and fossil transportation fuels. J. Clean Prod. 181, 337-351. https://doi.org/10.1016/j.jclepro.2018.01.211 
Feiz, R., 2016. Systems Analysis for Eco-Industrial Development: Applied on Cement and Biogas Production Systems (Doctoral thesis). Linköping University, Linköping, Sweden.

Feiz, R., Ammenberg, J., 2017. Assessment of feedstocks for biogas production, part I-A multi-criteria approach. Resources, Conservation and Recycling 122, 373-387. https://doi.org/10.1016/j.resconrec.2017.01.019

Frosch, R.A., Gallopoulos, N.E., 1989. Strategies for Manufacturing. Scientific American; (USA) 261. https://doi.org/10.1038/scientificamerican0989-144

Gasking, D.A.T., Jackson, A.C., 1962. Wittgenstein as a Teacher, in: Fann, K.T. (Ed.), Ludwig Wittgenstein: The Man and His Philosophy. Harvester Press, Sussex, England.

Graedel, T.E., Allenby, B.R., 1995. Industrial Ecology. Prentice Hall.

Guba, E.G., Lincoln, Y.S., 1989. Fourth generation evaluation. SAGE Publications, Newbury Park, USA.

Habermas, J., 2017. Truth and Justification, 1 edition. ed. Polity.

Healey, P., 1998. Building Institutional Capacity through Collaborative Approaches to Urban Planning. Environ Plan A 30, 1531-1546. https://doi.org/10.1068/a301531

Healey, P., de Magalhaes, C., Madanipour, A., Pendlebury, J., 2003. Deliberative policy analysis understanding governance network society, in: Hajer, M.A., Wagenaar, H. (Eds.), Deliberative Policy Analysis: Understanding Governance in the Network Society. Cambridge University Press, Cambridge.

Hertwich, E.G., Pease, W.S., Koshland, C.P., 1997. Evaluating the environmental impact of products and production processes: a comparison of six methods. Science of The Total Environment 196, 13 29. https://doi.org/10.1016/S0048-9697(96)05344-2

Hewes, A.K., Lyons, D.I., 2008. The Humanistic Side of Eco-Industrial Parks: Champions and the Role of Trust. Regional Studies 42, 1329-1342. https://doi.org/10.1080/00343400701654079

Huber, J., 2000. Towards industrial ecology: sustainable development as a concept of ecological modernization. Journal of Environmental Policy \& Planning 2, 269-285. https://doi.org/10.1080/714038561

Jacobsen, N.B., Anderberg, S., 2004. Understanding the Evolution of Industrial Symbiotic Networks: The Case of Kalundborg, in: Van Den Bergh, J.C.J.M., Janssen, M. (Eds.), Economics of Industrial Ecology: Materials, Structural Change, and Spatial Scales. MIT Press, Massachusetts Institute of Technology, pp. 313-335.

Jelinski, L.W., Graedel, T.E., Laudise, R.A., McCall, D.W., Patel, C.K., 1992. Industrial ecology: concepts and approaches. PNAS 89, 793-797. https://doi.org/10.1073/pnas.89.3.793

Klenk, N., Meehan, K., 2015. Climate change and transdisciplinary science: Problematizing the integration imperative. Environmental Science \& Policy 54, 160-167. https://doi.org/10.1016/j.envsci.2015.05.017

Korhonen, J., 2004a. Industrial ecology in the strategic sustainable development model: strategic applications of industrial ecology. Journal of Cleaner Production, Applications of Industrial Ecology 12, 809-823. https://doi.org/10.1016/j.jclepro.2004.02.026

Korhonen, J., 2004b. Theory of industrial ecology. Progress in Industrial Ecology, an International Journal 1, 61-88. https://doi.org/10.1504/PIE.2004.004672

Kügemann, M., Polatidis, H., 2020. Multi-Criteria Decision Analysis of Road Transportation Fuels and Vehicles: A Systematic Review and Classification of the Literature. Energies 13, 157. https://doi.org/10.3390/en13010157

Kumar, A., Sah, B., Singh, A.R., Deng, Y., He, X., Kumar, P., Bansal, R.C., 2017. A review of multi criteria decision making (MCDM) towards sustainable renewable energy development. Renewable and Sustainable Energy Reviews 69, 596-609. https://doi.org/10.1016/j.rser.2016.11.191

Lang, D.J., Wiek, A., Bergmann, M., Stauffacher, M., Martens, P., Moll, P., Swilling, M., Thomas, C.J., 2012. Transdisciplinary research in sustainability science: practice, principles, and challenges. Sustain Sci 7, 25-43. https://doi.org/10.1007/s11625-011-0149-x 
Lozano, R., Carpenter, A., Huisingh, D., 2015. A review of 'theories of the firm' and their contributions to Corporate Sustainability. Journal of Cleaner Production, Bridges for a more sustainable future: Joining Environmental Management for Sustainable Universities (EMSU) and the European Roundtable for Sustainable Consumption and Production (ERSCP) conferences 106, 430-442. https://doi.org/10.1016/j.jclepro.2014.05.007

Lundberg, S., Bergman, M., 2011. Tender Evaluation and Award Methodologies in Public Procurement (SSRN Scholarly Paper No. ID 1831143). Social Science Research Network, Rochester, NY.

Magnusson, T., Andersson, H., Ottosson, M., 2019. Industrial ecology and the boundaries of the manufacturing firm. Journal of Industrial Ecology. https://doi.org/10.1111/jiec.12864

Martinez-Alier, J., Munda, G., O’Neill, J., 1998. Weak comparability of values as a foundation for ecological economics. Ecological Economics 26, 277-286. https://doi.org/10.1016/S09218009(97)00120-1

Matson, P., 2001. Environmental Challenges for the Twenty-First Century: Interacting Challenges and Integrative Solutions. Ecology L.Q. 27, 1179-1190.

Mendoza, G.A., Macoun, P., Prabhu, R., Sukadri, D., Purnomo, H., Hartanto, H., 1999. Guidelines for applying multi-criteria analysis to the assessment of criteria and indicators (No. ISBN: 979-876427-7). Center for international forestry research, Jakarta, Indonesia.

Mendoza, G.A., Martins, H., 2006. Multi-criteria decision analysis in natural resource management: A critical review of methods and new modelling paradigms. Forest Ecology and Management 230, 1-22. https://doi.org/10.1016/j.foreco.2006.03.023

Mirata, M., 2005. Industrial Symbiosis - A Tool for More Sustainable Regions? (thesis/doccomp). Lund University, Lund, Sweden.

Mirata, M., 2004. Experiences from early stages of a national industrial symbiosis programme in the UK: determinants and coordination challenges. Journal of Cleaner Production, Applications of Industrial Ecology 12, 967-983. https://doi.org/10.1016/j.jclepro.2004.02.031

Mirata, M., Emtairah, T., 2005. Industrial symbiosis networks and the contribution to environmental innovation: The case of the Landskrona industrial symbiosis programme. Journal of Cleaner Production, 10th Anniversary of the International Institute for Industrial Environmental Economics (IIIEE): Management and policy for sustainable consumption and production 13, 993-1002. https://doi.org/10.1016/j.jclepro.2004.12.010

Paquin, R.L., Howard Grenville, J., 2012. The Evolution of Facilitated Industrial Symbiosis. Journal of Industrial Ecology 16, 83-93. https://doi.org/10.1111/j.1530-9290.2011.00437.x

Park, J., Duque-Hernández, J., Díaz-Posada, N., 2018. Facilitating Business Collaborations for Industrial Symbiosis: The Pilot Experience of the Sustainable Industrial Network Program in Colombia. Sustainability 10, 3637. https://doi.org/10.3390/su10103637

Park, J.M., Park, J.Y., Park, H.-S., 2016. A review of the National Eco-Industrial Park Development Program in Korea: progress and achievements in the first phase, 2005-2010. J. Clean Prod. 114, 3344. https://doi.org/10.1016/j.jclepro.2015.08.115

Pohekar, S.D., Ramachandran, M., 2004. Application of multi-criteria decision making to sustainable energy planning-A review. Renewable and Sustainable Energy Reviews 8, 365-381. https://doi.org/10.1016/j.rser.2003.12.007

Pohl, C., 2011. What is progress in transdisciplinary research? Futures, Wendell Bell 43, 618-626. https://doi.org/10.1016/j.futures.2011.03.001

Pohl, C., Hirsch Hadorn, G., 2008. Methodological challenges of transdisciplinary research. Natures Sciences Sociétés 16, 111-121.

Porter, M.E., van der Linde, C., 1995. Green and Competitive: Ending the Stalemate. Harvard Business Review.

Ranger, S., Kenter, J.O., Bryce, R., Cumming, G., Dapling, T., Lawes, E., Richardson, P.B., 2016. Forming shared values in conservation management: An interpretive-deliberative-democratic approach 
to including community voices. Ecosystem Services, Shared, plural and cultural values 21, 344357. https://doi.org/10.1016/j.ecoser.2016.09.016

Raymond, C.M., Kenter, J.O., 2016. Transcendental values and the valuation and management of ecosystem services. Ecosystem Services, Shared, plural and cultural values 21, 241-257. https://doi.org/10.1016/j.ecoser.2016.07.018

Roberts, N., 2000. Wicked Problems and Network Approaches to Resolution. International Public Management Review 1, 1-19.

Short, S.W., Bocken, N.M.P., Barlow, C.Y., Chertow, M.R., 2014. From Refining Sugar to Growing Tomatoes Industrial Ecology and Business Model Evolution. J. Ind. Ecol. 18, 603-618. https://doi.org/10.1111/jiec.12171

Spekkink, W., 2016. Industrial symbiosis as a Social Process (Doctoral thesis). Erasmus University Rotterdam, Rotterdam, Netherlands.

Spekkink, W., 2015. Building capacity for sustainable regional industrial systems: an event sequence analysis of developments in the Sloe Area and Canal Zone. Journal of Cleaner Production, Special Volume: Support your future today! Turn environmental challenges into opportunities. 98, 133144. https://doi.org/10.1016/j.jclepro.2014.08.028

Spekkink, W., 2013. Institutional capacity building for industrial symbiosis in the Canal Zone of Zeeland in the Netherlands: a process analysis. Journal of Cleaner Production 52, 342-355. https://doi.org/10.1016/j.jclepro.2013.02.025

Stafford-Smith, M., Griggs, D., Gaffney, O., Ullah, F., Reyers, B., Kanie, N., Stigson, B., Shrivastava, P., Leach, M., O'Connell, D., 2017. Integration: the key to implementing the Sustainable Development Goals. Sustain Sci 12, 911-919. https://doi.org/10.1007/s11625-016-0383-3

Strauss, L., 1953. Natural Right and History, Reissue edition. ed. University of Chicago Press, Chicago.

UNEP/SETAC, 2005. Life cycle approaches. The road from analysis to practice. UNEP/SETAC Life Cycle Initiative: Paris, France.

United Nations, 1987. Our Common Future (Annex No. A/42/427). World Commission on Environment and Development, Oslo, Norway.

van Berkel, R., Fujita, T., Hashimoto, S., Fujii, M., 2009. Quantitative Assessment of Urban and Industrial Symbiosis in Kawasaki, Japan. Environ. Sci. Technol. 43, 1271-1281. https://doi.org/10.1021/es803319r 


\section{Papers}

The papers associated with this thesis have been removed for copyright reasons. For more details about these see:

http://urn.kb.se/resolve?urn=urn:nbn:se:liu:diva-164967 


\section{FACULTY OF SCIENCE AND ENGINEERING}

Linköping Studies in Science and Technology, Licentiate Thesis No. 1875, 2020 Department of Management and Engineering

Linköping University

SE-581 83 Linköping, Sweden

wwW.liu.se 